\title{
Spatial distribution of crystalline corrosion products formed during corrosion of stainless steel in concrete
}

Marijana Serdar ${ }^{\mathrm{a}}$, Cagla Meral ${ }^{\mathrm{b}}$, Martin Kunz ${ }^{\mathrm{c}}$, Dubravka Bjegovic ${ }^{\mathrm{a}}$, Hans-Rudolf Wenk ${ }^{\mathrm{d}}$, Paulo J.M. Monteiro ${ }^{\mathrm{e}}$

${ }^{\mathrm{a}}$ Department of Materials, Faculty of Civil Engineering, University of Zagreb, 10000 Zagreb, Croatia, mserdar@grad.hr

${ }^{\mathrm{b}}$ Middle East Technical University, department of civil engineering, Ankara

${ }^{\mathrm{c}}$ Lawrence Berkeley National Laboratory, 1 Cyclotron Road, Berkeley, CA 94720, United States

${ }^{\mathrm{d}}$ Department of Earth and Planetary Science, University of California, Berkeley, CA 94720, United States

${ }^{\mathrm{e}}$ Department of Civil and Environmental Engineering, University of California, Berkeley, CA 94720, United States

\begin{abstract}
The mineralogy and spatial distribution of nano-crystalline corrosion products that form in the steel/concrete interface was characterized using synchrotron X-ray micro-diffraction $(\mu$ XRD). Two types of low-nickel high-chromium reinforcing steels embedded into mortar and exposed to $\mathrm{NaCl}$ solution were investigated. Corrosion in the samples was confirmed by electrochemical impedance spectroscopy (EIS). $\mu$-XRD revealed that goethite $(\alpha-\mathrm{FeOOH})$ and akaganeite $(\beta-\mathrm{FeOOH})$ are the main iron oxide-hydroxides formed during the chlorideinduced corrosion of stainless steel in concrete. Goethite is formed closer to the surface of the steel due to the presence of chromium in the steel, while akaganeite is formed further away from the surface due to the presence of chloride ions. Detailed microstructural analysis is shown and discussed on one sample of each type of steel.
\end{abstract}


Key words: B: Backscattered Electron Imaging, B: X-ray micro-diffraction; C: corrosion; E:concrete; stainless steel.

\section{Introduction}

In non-carbonated and chloride-free concrete, embedded steel reinforcement is protected from corrosion by a protective oxide film that forms on the steel surface. However, in less-thanideal conditions this is not the case. A decrease in concrete alkalinity may cause failure of the stable chemical environment around the steel reinforcement. Also, a rise of the concentration of chloride ions above a threshold value in the vicinity of steel reinforcement may lead to a localised breakage of the passive layer [1]. Once the passive layer is dissolved or broken corrosion is initiated, and a second stage of corrosion starts, i.e., the corrosion propagation period, during which corrosion products are formed on the surface of the steel [2]. These corrosion products are mainly iron oxides and iron oxide-hydroxides, which have a larger specific volume than pure iron. The resulting volume expansion during the build-up of corrosion products creates radial pressure at the steel/concrete interface, leading to concrete cracking and delaminating, and eventually structural instability and failure [3]. Models that consider the radial pressure at the interface between the cement matrix and reinforcing steelwhich leads to tensile stresses greater than the concrete tensile strength and thus cracking- 
take into account properties of concrete (e.g., residual compressive and tensile strength, stiffness, modulus of elasticity) and properties of corrosion products (e.g., rate of formation, depth of penetration into the matrix, volume, and morphology of corrosion products) [4-11]. Due to the critical role that corrosion products play in understanding the propagation of corrosion, cracking and the eventual failure of concrete, several comprehensive studies were performed to characterize the different iron oxides and iron oxide-hydroxides that form during corrosion of carbon steel reinforcement [13-17] and weathering steels [12,18,19]. However, previous studies investigating corrosion products formed on carbon steel reinforcement in concrete [13-16] have not reported the spatial distribution of the crystalline phases in the corrosion products near the steel-cement matrix interface. This information is critical to better understand the corrosion process, the formation of corrosion products, and the generation of stress on the interface leading to concrete cracking.

Nowadays, stainless steels are widely utilized as reinforcement instead of carbon steel, especially when durability due to aggressive environment exposure is a concern. Because of rising nickel prices, however, new types of corrosion resistant steels with lower percentages of alloying elements have been developed, e.g., low-nickel, high-chromium corrosionresistant steels, which can be a cost-effective corrosion resistant alternative to highly alloyed stainless steels. So far, published research on these types of steel as concrete reinforcement has focused on the corrosion initiation phase, mainly on the characterization of the passive film, and on the critical conditions for the onset of corrosion [20-24]. Long-term research of corrosion behaviour of these steels in concrete is very scarce, especially those aiming at evaluating the real-time propagation of corrosion and the formation of corrosion products. Until now, research on laboratory samples and long-term exposure of real concrete reinforced structures to marine environments have shown that, besides longer initiation periods, these steels have a prolonged propagation period (i.e., more time is needed to achieve a certain level 
of corrosion activity) $[25,26]$. The available literature on corrosion products formed under the influence of alloying elements concentrates mainly on synthesized iron oxide-hydroxides, created and tested under laboratory-controlled conditions [12, 27-31]. These studies have demonstrated that adding specific alloys influences the type of iron-hydroxide phases created during the corrosion process.

The present study aims at determining the type, morphology, and in-situ spatial distribution of the crystalline phases of corrosion products that form during natural (non-accelerated) corrosion of two types of low-Ni, high-chromium $\mathrm{Cr}$ corrosion resistant steel embedded in mortar. Reinforced mortar samples were exposed to an aggressive chloride solution for two years, during which their corrosion activity was confirmed by (1) monitoring the corrosion potential and (2) by analysing electrochemical impedance spectra (EIS) at the open circuit potential $\left(E_{\mathrm{OC}}\right)$. Next, corrosion products formed in the steel-cement matrix interface were analysed with synchrotron radiation to determine their type and distribution relative to the surface of the reinforcement. Using synchrotron-based X-ray micro-diffraction ( $\mu$-XRD), two-dimensional maps showing the distribution of crystalline phases with a high spatial resolution were obtained. Besides the $\mu$-XRD used for identification of crystalline phases, $\mathrm{X}$ ray micro-fluorescence $(\mu-\mathrm{XRF})$ was also used for elemental mapping to differentiate between corrosion products and the cement paste matrix, thus locating areas of interest (e.g., iron-rich or chromium-rich areas). Scanning Electron Microscopy (SEM) combined with Energy Dispersive Spectrometry (EDS) was used for imaging and to determine the chemical composition of recognized corrosion products.

\section{Experimental program}

\subsection{Materials}

Two types of low-Ni, high-Cr steel were studied. One of the steels had $10 \mathrm{wt} \% \mathrm{Cr}$ (UNS S41008, EN 1.4003) and the other 16 wt\% Cr (UNS S20430, EN 1.4597). Both steels had 
significantly lower $\mathrm{Ni}$ content compared to classical stainless steel (less than $2 \mathrm{wt} \%$, compared to typical alloyed stainless steel with 8 to 13 wt\%). Table 1 lists their chemical composition. Both tested steels are commercially available on the market as corrugated reinforcing steel, and both were embedded into the mortar as received from the manufacturer. The surface of the reinforcing steels was not additionally pre-treated, with an intention to simulate what would happen during real construction in the case of application of these steels as reinforcement. Production processes of both of the tested steels are protected by the producers. Based on the appearance of the surface of the steel, it could be assumed that $10 \%$ wt $\mathrm{Cr}$ steel was not pickled, while $16 \%$ steel was pickled in the production phase.

The mortar used to embed the steels was prepared using cement CEM I 42.5 (cement without mineral admixture, similar to ASTM cement Type I), with a 0.7 water-to-cement ratio. Crushed limestone with a maximum particle size of $4 \mathrm{~mm}$ was chosen as the aggregate. The mortar mix proportion was chosen so that the ratio between constituent materials (water, cement and aggregate) was identical to the concrete labelled $\mathrm{C}(0.7)$ according to European standard EN 1766: 2000. In this standard, the preparation of reference concrete is described, which is used to perform comparative tests for evaluating the influence of products and systems for repair and protection of reinforced concrete structures. Therefore, to evaluate the influence of corrosion resistant steel composition on the corrosion behaviour of reinforced concrete and to keep the concrete quality constant for both steel types, a similar mortar to that $\mathrm{C}(0.7)$ of known properties was prepared. Corrosion was not accelerated electrochemically; rather, it was allowed to initiate and propagate naturally. To obtain a significant amount of corrosion products in a reasonable time, a mortar with high water-to-cement ratio was used. It is assumed that a better quality concrete would not change the morphology or chemical composition of the corrosion products; however, it would prolong the time to onset of active corrosion, change the properties of the interfacial zone between steel and matrix, and 
influence the mobility of ions inside the cement matrix. However, since the aim of the paper is to compare two different types of steel in the same mortar mixture, it can be expected that this influence would be similar for both steel types.

The mortar was cured for 28 days in a humidity chamber, with controlled humidity (95\% RH) and temperature $\left(20 \pm 2^{\circ} \mathrm{C}\right)$. After 28 days, the compressive strength of the mortar was measured as 32.7 MPa. The mortar also showed a low resistance to chloride penetration (nonsteady state chloride migration coefficient tested according to NT BUILD 492; measured as $\left.2 \times 10^{-11} \mathrm{~m}^{2} \mathrm{~s}^{-1}\right)$.

\subsection{Preparation of the samples}

The $14 \mathrm{~mm}$-diameter steel rebar from the selected two different steels were cut into $100 \mathrm{~mm}$ long pieces, providing an approximate steel testing area of $45.5 \mathrm{~cm}^{2}$ for each segment. A copper wire was welded to the top end of each segment for the electrical connection. The weld was protected with a polyester-based sealing material. This connection was necessary to monitor the corrosion potential and obtain impedance spectra of the steel during the twoyear-long exposure of the samples to aggressive conditions that simulated a marine environment. The steel segments were placed into $40 \mathrm{~mm}$-diameter and $140 \mathrm{~mm}$-long plastic moulds and fresh mortar was then placed into the moulds embedding the steel. A special holder for moulds was prepared, consisting of 10 samples. The wire which was connected to the reinforcing steel for electrochemical testing was fixed on the bottom of the holder, to ensure that the steel will stay in the centre of the mould. Once the mortar was placed inside the mould, the mould holder with all samples was placed on a vibrating table to ensure full compaction of the samples. Samples were checked after demoulding, to ensure there were no visible defects of the samples. Three replica samples were prepared as described and were cured in a humidity chamber for 28 days with controlled humidity (95\% RH) and temperature $\left(20 \pm 2^{\circ} \mathrm{C}\right)$ and were subsequently partially submerged into a $3.5 \mathrm{wt} \% \mathrm{NaCl}$ 
solution $\left(0.6 \mathrm{~mol} \mathrm{dm}^{-3}\right)$. A schematic sketch of the sample assembly is shown in Fig. 1(a). Oxygen penetration was expected to proceed from the upper part of the samples and chloride penetration from the submerged part of the specimen. Based on the corrosion potential measurement and impedance spectra data representative specimens were chosen for detailed microstructural analysis, and it is expected that these specimens can be a representatives of the group. After two years of exposure, this representative specimen of each type of steel was cut into 1-cm-thick slices. To ensure that all voids in the matrix as well as the interface were filled with epoxy, one side of the slice was vacuum impregnated with low-viscosity epoxy resin. Next, the surfaces were carefully polished on a grinding plate with 20,9 , and $3 \mu \mathrm{m}$ $\mathrm{Al}_{2} \mathrm{O}_{3}$ powder. The final polish was completed using an oil-based paste with $0.25 \mu \mathrm{m}$ diamond abrasives. During the grinding and polishing, kerosene was used instead of water to avoid any further reaction in the specimen. To prevent charging, a $20 \mathrm{~nm}$-thick coating of carbon was applied on the specimens before conducting the SEM investigations. Fig. 1(b) shows the specimens as used in the microscopic investigations.

It has to be noted that, even though samples were impregnated with epoxy and kerosene was used during grinding and polishing, the process of cutting and grinding the sample may have induced additional cracks in the sample and some short exposure to oxygen may have changed the micro-structure of the products. This surely is one of the main drawbacks in using methods that need detailed and destructive sample preparation when investigating corrosion of reinforcing steel in concrete. However, high spatial resolution and the possibility of phase identification and mapping is unique to this method, which is why it was used for this specific purpose.

\subsection{Monitoring corrosion potential and impedance spectra}

During the exposure, the corrosion activity of reinforcing steels was monitored by measuring open-circuit potential $\left(\mathrm{E}_{\mathrm{OC}}\right)$ and by performing electrochemical impedance spectroscopy 
(EIS). A standard three-electrode system with a titanium mesh as a counter and a saturated calomel electrode (SCE) as a reference electrode was used. All potentials reported refer to the SCE. EIS measurements were performed in the frequency range between $100 \mathrm{kHz}$ and 0.1 $\mathrm{mHz}$ with the ac perturbation $\pm 10 \mathrm{mV}$. The impedance spectra fitting was carried out using the commercial software ZView.

\subsection{Scanning Electron Microscope (SEM) and Energy Dispersive Spectrometry (EDS)}

The SEM and EDS investigations were performed at the Department of Earth and Planetary Science at the University of California, Berkeley. The SEM was operated in backscatter mode, at an accelerating voltage of $15 \mathrm{kV}$ for imaging and $25 \mathrm{kV}$ for elemental analysis of the corrosion products. For imaging and microstructure investigations, magnifications in the range of 60 to $1000 \mathrm{x}$ were used with the probe current ranging between $500 \mathrm{pA}$ and $2 \mathrm{nA}$. The EDS point analysis and multi-element mapping were employed at specific positions on the sample to obtain the elemental analysis of corrosion products at the steel/cement matrix interface. Element mapping was performed at high energy $(25 \mathrm{kV})$ and high probe current (around $3.0 \mathrm{nA}$ ) to optimize the counting statistics.

\subsection{Micro X-ray Diffraction ( $\mu$-XRD) and micro X-ray Fluorescence ( $\mu$-XRF)}

Synchrotron $\mu$-XRD measurements, carried out on beamline 12.3.2 at the Advanced Light Source (ALS), Lawrence Berkeley National Laboratory [32,33], were used to characterize the corrosion products and to identify their spatial distribution. Beamline 12.3.2 offers the ability to operate with polychromatic $(5-22 \mathrm{keV})$ or monochromatic beams $[34,35]$. In the case of the $10 \mathrm{wt} \% \mathrm{Cr}$ steel, a $450 \mu \mathrm{m} \times 550 \mu \mathrm{m}$ area scan was collected, with a $20 \mu \mathrm{m}$ step size in the $x$-direction and a $50 \mu \mathrm{m}$ step size in the $y$-direction. In the case of the $16 \mathrm{wt} \% \mathrm{Cr}$ steel, two $500 \mu \mathrm{m} \times 400 \mu \mathrm{m}$ area scans were collected, with a $20 \mu \mathrm{m}$ scan step in the $x$ direction and a $100 \mu \mathrm{m}$ scan step in the $y$-direction. A diffraction pattern was collected at each step using the Pilatus $1 \mathrm{M}$ detector $(169 \times 179 \mathrm{~mm}$ with $981 \times 1043$ pixels of $0.172 \mu \mathrm{m}$ 
edge length). The scans were done in reflection mode, using a monochromatic beam (energy $10 \mathrm{keV}, \lambda=1.23986 \AA$ ) while collecting diffraction data. The detector was positioned at an angle $2 \theta$ of $47^{\circ}$ with respect to the incident beam. The angle of incident beam relative to the sample surface was $5^{\circ}$. The sample to detector distance was $145.93 \mathrm{~mm}$. More details on the general experimental set-up for beamline 12.3.2 can be found in Kunz et al. [33].

Although beamline 12.3.2 is optimized for $\mu$-XRD, it also allows collection of fluorescence signals through a VORTEX Si-drift detector that can be used to locate areas enriched with elements heavier than $\mathrm{Ca}(Z>20)$. In the present study, $\mu-\mathrm{XRF}$ was employed for the localization of elements of interest; this was done to differentiate the area of corrosion products from the cement matrix and pure steel. In this way, $\mu$-XRF maps helped to correlate sample positions during the $\mu$-XRD experiment with regions of interest identified in backscattered SEM images.

\section{Results and Discussion}

\subsection{Corrosion activity}

Fig. 2 shows representative results of $E_{\mathrm{OC}}$ time dependence, obtained from parallel measurements performed on 3 identical samples for each of the steel embedded into mortar, during 24 months of exposure to $3.5 \mathrm{wt} \% \mathrm{NaCl}$ solution. It can be observed that for the entire exposure time the potential of the $16 \mathrm{wt} \% \mathrm{Cr}$ steel was more anodic than the potential of the $10 \mathrm{wt} \% \mathrm{Cr}$ steel. After 24 months of exposure both the potential of the $10 \mathrm{wt} \% \mathrm{Cr}$ steel and $16 \mathrm{wt} \% \mathrm{Cr}$ steel decreased compared to the values after one month of exposure, but the latter value was still significantly more anodic than the former. The change of $E_{\mathrm{OC}}$ towards more negative values can be considered as indicative of depassivation of steel and initiation of localized corrosion. In this study we focused on the time-dependence of the potential where a rapid decrease of the potential is interpreted as destabilization or breakdown of the passive film and initiation of pitting corrosion. This interpretation is further supported by EIS results. 
EIS spectra for $10 \mathrm{wt} \% \mathrm{Cr}$ steel and $16 \mathrm{wt} \% \mathrm{Cr}$ steel after one month of exposure are presented in Fig. 3. After one month of exposure, a passive state is assumed for both steels. An electrical circuit (EC) was used to describe the behaviour of the tested steels and is shown on Fig. 3(a). In the electrical circuit, constant-phase elements (CPE) were used instead of the pure capacitance to take into account the inhomogeneity present at the reinforcement/pore solution interface [36]. The impedance of a $\mathrm{CPE}$ is defined as $Z_{\mathrm{CPE}}=\left[\mathrm{CPE}(j \omega)^{n}\right]^{-1}[37]$. During the fitting process, values of $n$ were smaller than 1 for both samples, indicating that the behavior of the system is not purely capacitive and that CPE should be used. Furthermore, this analysis of the proposed electrical circuit yielded fitted data with the error below $10 \%$ for all parameters. The accuracy of fitting is illustrated in Fig. 3(a) and 3(b), with experimental values presented as symbols and fitted values as lines. The physical meaning of the components in the proposed circuit during the passive state is the following: resistance $R_{\text {mortar }}$ can be related to the resistance of testing solution and mortar. The first time constant parameters (resistance $R_{1}$ and constant phase element $\mathrm{CPE}_{1}$ ) appearing at the intermediate frequencies (between $10 \mathrm{~Hz}$ and $10^{-1} \mathrm{~Hz}$ ) were attributed to the redox transformation which occurs on the outer region of the passive layer $[23,24]$. The second time constant parameters (resistance $R_{2}$ and constant-phase element $\mathrm{CPE}_{2}$ ) appearing at the low frequencies (between $10^{-1}$ and $10^{-3} \mathrm{~Hz}$ ) were attributed to the non-ideal interfacial capacitance of the steel surface and charge transfer resistance that reflects the corrosion resistance of the steel surface controlled by the properties of the passive film [22,24].

Fig. 4 presents the impedance spectra after 24 months of exposure for $10 \mathrm{wt} \% \mathrm{Cr}$ steel and 16 wt\% $\mathrm{Cr}$ steel, respectively. An electrical circuit was used to describe the behaviour of the tested steels and is shown on Fig. 4(a). Constant-phase elements CPE instead of the pure capacitance were used for longer exposure times, based on the same rationale used in the shorter exposure period. Here, the first time constant parameters (resistance $R_{1}$ and constant 
phase element $\mathrm{CPE}_{1}$ ) appearing at the intermediate frequencies (between $10 \mathrm{~Hz}$ and $10^{-2} \mathrm{~Hz}$ ) were attributed to the layer of corrosion products formed at the reinforcing steel surface, while the second time constant parameters (resistance $R_{2}$ and constant-phase elements $\mathrm{CPE}_{2}$ ) appearing at the low frequencies (between $10^{-2} \mathrm{~Hz}$ and $10^{-4} \mathrm{~Hz}$ ) were attributed to the sum of processes appearing at the pitted and passive area [38]. The accuracy of fitting is illustrated in Figs. 4(a) and (b), with experimental values presented as symbols and fitted values as lines (obtained error below 10\% for all parameters).

Table 2 shows the best-fit parameters obtained by fitting spectra measured after one month while Table 3 displays the respective values after 24 months of exposure for both types of steel. Values of resistance are expressed over a whole surface of exposed steel (steel testing area of $45.5 \mathrm{~cm}^{2}$ ). The constant-phase element values, obtained by fitting the spectra to proposed EC, were used to calculate the capacitance values, using the equation developed by Farcas et al [37]. The resistance of the mortar and electrolyte $R_{\text {mortar }}$, is similar for both steels, with values being slightly higher in the case of $10 \mathrm{wt} \% \mathrm{Cr}$ steel at the beginning of the exposure, but declining over time for both specimens. The variation of these resistances can be attributed to the poor quality of the mortar as water saturation and salt penetration inside the matrix caused the increase of the conductivity of the mortar. It is also possible that the variation in resistances is partly caused by varying distances between reference and working electrode due to the inability to perfectly replicate the electrochemical cell parameters during each testing. A comparison of resistances $R_{2}$ after one month of exposure, when both steels are passive, demonstrates that the charge transfer resistance of the passive film formed on 16 $\mathrm{wt} \% \mathrm{Cr}$ steel is two orders of magnitude higher than of the $10 \mathrm{wt} \% \mathrm{Cr}$ steel $\left(182.2 \mathrm{k} \Omega \mathrm{cm}^{2}\right.$ compared to $14.1 \mathrm{M} \Omega \mathrm{cm}^{2}$ ). This significant difference can be attributed to the formation of a more stable Cr-rich passive film in the case of $16 \mathrm{wt} \% \mathrm{Cr}$ steel compared to the case of 10 wt $\% \mathrm{Cr}$ steel [21]. The resistances $R_{1}$ after one month of exposure have comparable values for 
both tested steels (several $\mathrm{k} \Omega \mathrm{cm}^{2}$ ), supporting the attribution of this resistance to the redox transformation occurring on the surface of the oxide film formed on both types of steel.

After 24 months of exposure, the values of resistance $R_{1}$, ascribed to the layer of corrosion products, are higher in the case of $16 \mathrm{wt} \% \mathrm{Cr}$ steel than in the case of $10 \mathrm{wt} \% \mathrm{Cr}$ steel, 26.7 $\mathrm{k} \Omega \mathrm{cm} 2$ and $16.7 \mathrm{k} \Omega \mathrm{cm}^{2}$, respectively. There was an even great discrepancy in the values of capacitance $C_{1}$ measured: $2 \mathrm{mFcm}^{-2}$ for $10 \mathrm{wt} \% \mathrm{Cr}$ steel and $0.1 \mathrm{mFcm}^{-2}$ for $16 \mathrm{wt} \% \mathrm{Cr}$ steel. Obtained values of capacitance were similar to the values obtained for carbon and corrosionresistant steels during long-term exposure to aggressive environment [39].

A higher value of capacitance obtained for $10 \mathrm{wt} \% \mathrm{Cr}$ steel that for $16 \mathrm{wt} \%$ steel indicates formation of a highly porous and heterogeneous layer of corrosion products. The resistance $R_{1}$ of $16 \mathrm{wt} \% \mathrm{Cr}$ steel is higher than that of $10 \mathrm{wt} \% \mathrm{Cr}$ steel, with significantly lower capacitance of this layer, indicating that the layer of corrosion products formed in the case of $16 \mathrm{wt} \% \mathrm{Cr}$ steel is more homogeneous and probably less porous. A comparison of the EIS parameters of the second time constant $\left(R_{2}\right.$ and $\left.C_{2}\right)$ obtained for both types of steel after 24 months of exposure also revealed significantly higher resistance and significantly lower capacitance of the pitted and passive area of $16 \mathrm{wt} \% \mathrm{Cr}$ steel compared to $10 \mathrm{wt} \% \mathrm{Cr}$ steel. Therefore, even though the corrosion initiated and propagated for both steel specimens, the corrosion resistance of the $16 \mathrm{wt} \% \mathrm{Cr}$ steel was still significantly higher than that of the $10 \mathrm{wt} \% \mathrm{Cr}$ steel, even during the corrosion propagation period. Higher corrosion resistance of this steel during passivity is attributed to the composition of the passive film and is dependent on the chemical composition of the bulk material [20-22].

\subsection{Phase distribution}

Backscattered SEM (BSE) images (Figs. 5 and 6) were collected at low magnification (around 60X), which allowed for differentiation between phases in the sample (the steel is bright, the iron-rich interface with corrosion products are light grey, and the cement matrix is dark grey), 
and the correlation of the BSE image with $\mu$-XRF maps. Fig. 5 shows a backscatter image of the $10 \mathrm{wt} \% \mathrm{Cr}$ steel and the mortar interface (a) together with the element mapping of (b) Ca, (c) $\mathrm{Fe}$, and (d) $\mathrm{Cr}$, obtained by $\mu-\mathrm{XRF}$ of the same area. To allow comparison of the distribution of elements throughout the sample, the intensity of each element on a specific map-point was normalized relative to the maximum intensity of this element obtained on the mapped area, which explains the scale bar from 0 to 100 shown below the images. Note that the corrosion products are propagating from the steel surface through the cement matrix in a $\sim 0.5 \mathrm{~mm}$ thick layer.

Fig. 6 shows the BSE image of the $16 \mathrm{wt} \% \mathrm{Cr}$ steel and the mortar interface (a) together with the element mapping of (b) $\mathrm{Ca}$, (c) $\mathrm{Fe}$, and (d) $\mathrm{Cr}$, obtained by $\mu$-XRF of the same area. On this steel, corrosion products are propagating from the steel surface through the cement matrix in $\mathrm{a} \sim 0.4 \mathrm{~mm}$ thick layer. The numbers on the BSE images and Fe and $\mathrm{Cr}$ map on Fig. 5 and 6 denote the spots where diffraction patterns were collected [shown below in Fig. 8(a) and (b)]. These specific locations were chosen depending on the relative amount of $\mathrm{Fe}$ and $\mathrm{Cr}$, and their vicinity to the surface of the reinforcing steel. Positions 1 and 2 are close to the steel surface. Positions 3 and 4 are in the corrosion products/cement paste interface. Monochromatic diffraction measurements produced smooth Debye-Scherrer rings, revealing that corrosion products were nanocrystalline and that the monochromatic beam $(2 \times 20 \mu \mathrm{m})$ is appropriate for further characterization of these products. The obtained powder diffraction patterns covered a $2 \theta$ range of $8^{\circ}-60^{\circ}$, corresponding to $1.2<d<8.5 \AA$. Fig. 7 (a) shows an example of a diffraction pattern obtained with the instrument set up described in Section 2.5. Integration along the azimuthal direction leads to a regular one-dimensional intensity versus $d$-spacing or $2 \theta$ powder diffraction pattern. For phase identification, peak positions were compared against a crystal structure database, available as a part of the ALS in-house written $\mu$-XRD analysis software (XMAS) [32]. Proper phase identification requires calibration of 
the instrumental geometry; in this case, this was accomplished through the diffraction patterns of $\mathrm{Si}$ and $\mathrm{Al}_{2} \mathrm{O}_{3}$.

Table 4 shows the main crystalline phases observed in the corrosion layer and the $d$-spacing and Miller indices of their high-intensity finger-print reflections that were used to identify them $[40,41]$. Other phases usually found as corrosion products display only high angle, low $d$-spacing reflections, which are difficult to use phase identification due to strong peak overlap at low $d$-spacings. Fig. 7(b) and (c) show identified diffraction rings for dolomite (aggregate) and akaganeite (corrosion products), respectively. In addition to the phases related to the corrosion products, the investigated samples were prepared from reinforced mortar, resulting in the observation of many phases related to the cement matrix and the aggregates. Dolomite and halite, due to their high crystallinity, showed the strongest peaks in the $\mu-\mathrm{XRD}$ pattern and created strong individual spots, as opposed to the nanocrystalline corrosion products, which created smooth rings on the diffraction image. As hydration products and aggregates are not the subject of this research, their peaks were subtracted from diffraction patterns and are not displayed in the patterns shown in Fig. 8(a) and (b).

Fig. 8(a) and (b) show $\mu$-XRD patterns, which were obtained by integration over a $2 \theta$ range of $8^{\circ}-60^{\circ}$, corresponding to $1.2<d<8.5 \AA$, performed on a diffraction pattern collected on locations specified with numbers 1 to 4 on Fig. 5 and 6. The main phases were identified and their characteristic reflections are shown on the bottom of Fig. 8(a) and (b). The results of microdiffraction experiments presented in Fig. 8(a) and (b) show that akaganeite $\left(\mathrm{Fe}^{3+} \mathrm{O}(\mathrm{OH}, \mathrm{Cl})\right.$, also known as $\beta$ - $\left.\mathrm{FeOOH}\right)$ and goethite $(\alpha-\mathrm{FeOOH})$ are formed as the main crystalline phases of the corrosion products of chromium-rich steel in concrete exposed to a marine environment.

Previous studies performed on synthesized iron oxide-hydroxides indicated that chromium influences the formation of goethite as a predominant crystalline phase compared to other iron 
oxide-hydroxides [18]. Akaganeite was found to be the main phase when corrosion occurred in marine environments $[15-17,19]$. Therefore, the influence of the steel composition and the environment around the steel in concrete explains why mainly these two iron oxidehydroxides formed as corrosion product of chromium rich steel in concrete exposed to marine environment. In the case of the $10 \mathrm{wt} \% \mathrm{Cr}$ steel, chromite $\left(\mathrm{FeCr}_{2} \mathrm{O}_{4}\right)$ is also identified at the edge of this reinforcing steel. Even though chromite and magnetite $\left(\mathrm{Fe}_{3} \mathrm{O}_{4}\right)$ have similar diffraction patterns, the $d$-spacings of the phase observed here matched the ones of chromite better than magnetite. Also, EDS performed on the phase adjacent to the surface of the steel revealed high amounts of chromium, and the ratio between chromium and iron indicated chromite chemistry. Since chromite could potentially be a precipitate formed during production of this ferritic steel [42] and not a phase formed due to the corrosion process, it is not considered further.

Besides these phases, no other crystalline phases were found in any significant amount. In particular, the diffraction patterns suggest an absence of $\mathrm{Cr}$ or $\mathrm{Ni}$ oxide-hydroxides. This is attributed to the fact that other alloying metals are present in much lower amounts compared to iron. Compared to chromium, iron dissolves more readily and forms less stable compounds with oxides and hydroxides. These less stable compounds react more easily with chloride ions to form a soluble complex [3], which then precipitates in the pore solution away from the surface of the steel. This explains why iron-rich areas are found further away from the steel surface, while chromium-rich areas outside the steel are found only in a thin layer in immediate vicinity of the steel surface. Furthermore, the diffraction pattern shown in Fig. 8(a) and (b) seem to suggest that akaganeite and goethite grow by different mechanisms, depending on their proximity to the steel surface and the amount of $\mathrm{Cr}$ and Fe available. In the case of $10 \mathrm{wt} \% \mathrm{Cr}$ steel, akaganeite peaks were found closer to the steel surface, but they tended to be weaker and broader. With further distance from the steel surface, akaganeite 
peaks increased in intensity and became sharper, indicating a higher crystallinity and larger grain size. In the case of $16 \mathrm{wt} \% \mathrm{Cr}$ steel, mostly goethite is found in those areas closer to the surface of the steel; its peaks have high intensities and are sharp, indicating that goethite is in a well-crystallized phase in the area around the surface of this steel. In contrast, further away from the surface of the steel, goethite peaks become weaker and broader and akaganeite peaks more intense and sharper.

To further investigate the distribution of these two phases, two-dimensional phase distribution maps [shown on Fig. 9 and 10] were extracted from the diffraction area scans by integrating the intensity over a single finger-print diffraction ring [as opposed to the patterns shown in Fig. 8(a) and (b), which were obtained by integration over the full range of $2 \theta$ measured]. This was done using the (101) reflection at $d$-spacing $4.20 \AA$ for goethite [40] and (512) reflection at $d$-spacing $1.63 \AA$ for akaganeite [41]. Fig. 9 shows detailed investigation of an area of interest, performed using $\mu-\mathrm{XRF}$ and $\mu$-XRD on the $10 \mathrm{wt} \% \mathrm{Cr}$ steel reinforced mortar sample. The area of interest is chosen based on the $\mu$-XRF maps (Fig. 5). The elemental maps for (a) $\mathrm{Fe}$, (b) $\mathrm{Cr}$, and (c) $\mathrm{Ca}$, obtained through $\mu$-XRF measurements are given on the lefthand side diagrams (with their scale bar), while corresponding intensity maps showing distribution of (d) chromite $\left(\mathrm{FeCr}_{2} \mathrm{O}_{4}\right)$, (e) akaganeite $(\beta$-FeOOH), and (f) goethite $(\alpha$ $\mathrm{FeOOH}$ ), obtained through $\mu-\mathrm{XRD}$ measurement, are given on the right-hand side diagrams. Fig. 10 shows detailed investigation of the area of interest performed using $\mu$-XRF and $\mu$ $\mathrm{XRD}$ on the $16 \mathrm{wt} \% \mathrm{Cr}$ steel reinforced mortar sample, which was chosen based on the $\mu$ XRF maps, presented in Fig. 6.

The elemental maps for (a) Fe and (b) Cr obtained through $\mu$-XRF measurements are given on the left-hand side diagrams (with their scale bar), while the corresponding intensity maps, showing distribution of (c) akaganeite and (d) goethite, obtained through $\mu$-XRD measurement, are given on the right-hand side diagrams. As shown in Figs. 9 and 10, a layer 
of goethite is observed next to the steel surface, which is followed by layers of akaganeite. Previous studies have demonstrated that large amounts of both dissolved iron species and high chloride concentrations are necessary for the formation of akaganeite [27,43]. In the investigated samples with embedded steels, it is possible that a large amount of dissolved iron and chloride ions could accumulate in the steel/cement mortar interface, thereby creating favourable conditions for akaganeite formation. The micro-diffraction experiments reported here show that the layer of goethite and the layer of akaganeite are negatively correlated, i.e., locations with higher amount of goethite have lower amounts of akaganeite, and vice versa. Further investigation of the corrosion products formed in the steel/concrete interface was conducted examined using SEM and EDS. During the microscopic investigation of the 10 wt\% $\mathrm{Cr}$ steel interface, needle-like crystals were found in voids and cracks close to the surface of the steel, as shown in Fig. 11. These typical needle-like crystals are usually identified as akaganeite crystals due to their specific morphology and the significant amount of chloride in their composition [13]. This is in agreement with the $\mu$-XRD results [Fig. 8(a)], which demonstrated that in the case of $10 \mathrm{wt} \% \mathrm{Cr}$ steel, akaganeite is found close to the surface of the steel. In the case of $16 \mathrm{wt} \% \mathrm{Cr}$ steel, no needle-like crystals were found close to the surface of the steel; rather these needle-like crystals formed further away of the surface in voids. They were usually found surrounded by platy-like crystals that did not have chlorides in their chemical composition. This is also in agreement with $\mu$-XRD results [Fig. 8(b)], which showed that goethite had formed closer to the surface and was then followed by layers of akaganeite. An image of these groups of crystals is given in Fig. 12.

Besides BSE images of needle-like and plate-like crystals formed around a void, Fig. 12 shows iron and chromium distribution maps of the crystals obtained by EDS. The maps show that a certain amount of chromium is present in corrosion products that formed during corrosion of $16 \mathrm{wt} \% \mathrm{Cr}$ steel. Previous research performed on synthesized particles of 
different iron oxide-hydroxide has shown that cations such as $\mathrm{Cr}^{3+}, \mathrm{Cu}^{2+}, \mathrm{Mn}^{2+}, \mathrm{Al}^{3+}$ can substitute for iron in goethite, akaganeite, lepidocrocite, or magnetite [18, 28-31]. Cook et al. [18] used Mössbauer and Raman spectrometry to characterize corrosion products that formed on weathering steel in natural environments, demonstrating that a layer of nano-sized chromium substituted goethite crystals formed close to the steel surface. They also prepared synthesized particles of goethite doped with $\mathrm{Cr}$ to show that incorporation of $\mathrm{Cr}$ changes the mean crystal size. Morales et al. [28] used transmission electron microscopy and Mössbauer spectroscopy on synthesized goethite samples and, based on the hyperfine parameters of the tested samples, demonstrated that most of the particles present in pure goethite are larger than $13 \mathrm{~nm}$; in Cr-substituted goethite, however, most of the particles ranged between 8 and $13 \mathrm{~nm}$. Previous studies [18,29] have hypothesized that the internal goethite layer (that layer close to the surface of the steel) contributed most heavily to the corrosion resistance of alloyed steels, thereby interfering with diffusion of chloride ions in the rust layer.

Based on the results from $\mu$ XRD and SEM coupled with EDS presented herein, it can be hypothesized that this layer of goethite with $\mathrm{Cr}$, found in the case of $16 \mathrm{wt} \% \mathrm{Cr}$ steel and absent in the case of $10 \mathrm{wt} \% \mathrm{Cr}$ steel, contributed to the decreased corrosion propagation of $16 \mathrm{wt} \% \mathrm{Cr}$ steel relative to that of $10 \mathrm{wt} \% \mathrm{Cr}$ steel, as shown by the impedance data (Table 2 and 3). Since these Cr-substituted iron oxide-hydroxides were until now only found on synthesized iron oxide-hydroxides, further research has to be performed on other reinforcing steel types with different $\mathrm{Cr}$ and Ni contents to confirm that such a substitution would occur naturally during corrosion of $\mathrm{Cr}$ alloyed steel in concrete under high $\mathrm{pH}$ and low oxygen availability. As earlier discussed, previous research on synthesized Cr-substituted iron oxidehydroxides [18,28,30,31] have shown that the presence of $\mathrm{Cr}$ influences the size of the crystals. A similar behavior could be expected in the case of corrosion products formed during corrosion of $\mathrm{Cr}$-rich reinforcing steel in concrete. This would have a tremendous 
influence in concrete structures since any variation in crystallite formation, size, and morphology could potentially lead to differences in pressure at the steel/concrete interface, consequently influencing the onset of the cracking of concrete to occur.

\section{Conclusions}

Our results showed that scanning $\mu$-XRD is a very useful tool for samples with nanocrystalline phases, enabling phase differentiation and 2-D distribution maps of corrosion products with high spatial resolution. Analysis of powder diffraction patterns revealed that the main phases formed during corrosion of two types of high-Cr, low-Ni corrosion resistant steels embedded in mortar were goethite and akageneite. Goethite is predominantly found closer to the surface of the steel and its growth is enhanced by the presence of chromium in the composition of reinforcing steel. Akageneite is found further away from the surface of the steel and its growth is attributed to the presence of chloride ions in the environment around the steel. In the case of steel with higher $\mathrm{Cr}$ content, corrosion products with $\mathrm{Cr}$ were identified using SEM and EDS.

Since the present work investigated a phenomenon only on a single set of samples, a follow up of the research would be to perform a statistical analysis to confirm reproducibility and repeatability of the applied experimental program.

\section{Acknowledgements}

This research was supported by Unity through Knowledge Fund (UKF), Croatian Ministry of Science, Education and Sport (Grant No. 73/10), and by scientific project "The Development of New Materials and Concrete Structure Protection Systems” (No. 082-0822161-2159), funded by Croatian Ministry of Education, Science and Sport. This publication was based on work supported in part by Award No. KUS-11-004021, made by King Abdullah University of Science and Technology (KAUST). The Advanced Light Source is supported by the Director, 
Office of Science, Office of Basic Energy Sciences, of the U.S. Department of Energy under Contract No. DE-AC02-05CH11231. 


\section{References}

[1] P.K. Mehta, P.J. Monteiro, Concrete: Microstructure, Properties, and Materials, McGraw-Hill, New York, 2006.

[2] K. Tuutti, Corrosion of steel in concrete, Tech. Report, Swedish Cement and Concrete Research Institute, Stockholm, 1982.

[3] A. Bentur, S. Diamond, N. Berke, Steel Corrosion in Concrete, Fundamental and Civil Engineering Practice, E \& FN Spoon, London, 1997.

[4] K. Bhargava, A.K. Ghosh, Y. Mori, S. Ramanujam, Modeling of time to corrosioninduced cover cracking in reinforced concrete structures, Cement Concr. Res. 35 (2005) $2203-2218$.

[5] T. Liu, R.W. Weyers, Modeling the dynamic corrosion process in chloride contaminated concrete structures, Cement Concr. Res. 28 (1998) 365-379.

[6] S. Caré, Q.T. Nguyen, V. L'Hostis, Y. Berthaud, Mechanical properties of the rust layer induced by impressed current method in reinforced mortar, Cement Concr. Res. 38 (2008) 1079-1091.

[7] H.S. Wong Y.X. Zhao, A.R. Karimi, N.R. Buenfeld, W.L. Jin: On the penetration of corrosion products from reinforcing steel into concrete due to chloride-induced corrosion, Corros Sci. 52 (2010) 2469-2480

[8] A. Michel, B.J. Pease, M.R. Geiker, H. Stang, J.F. Olesen: Monitoring reinforcement corrosion and corrosion-induced cracking using non-destructive x-ray attenuation measurements. Cement Concr. Res. 41 (2011) 1085-1094 
[9] Z.P. Bazant, Physical model for steel corrosion in concrete sea structures application, J Struct Div-ASCE 105 (1979) 1155-1166.

[10] C.L. Page, K.W.J. Treadaway, Aspects of the electrochemistry of steel in concrete, Nature 297 (1982), 109 - 115.

[11] A.A. Torres-Acosta, A.A. Sagues, Concrete cracking by localized steel corrosion Geometric effects, ACI Mater J 101 (2004), 501-507.

[12] A. Raman, S. Nasrazadani, L. Sharma, Morphology of rust phases formed on weathering steels in various laboratory corrosion tests, Metallography. 22 (1989) 79-96.

[13] D.A. Koleva, J. Hu, A.L.A. Fraaij, P. Stroeven, N. Boshkov, J.H.W. de Wit, Quantitative characterisation of steel/cement paste interface microstructure and corrosion phenomena in mortars suffering from chloride attack, Corros Sci. 48 (2006) 4001-4019.

[14] R. Vera, M. Villarroel, A.M. Carvajal, E. Vera, C. Ortiz, Corrosion products of reinforcement in concrete in marine and industrial environments, Mater Chem Phys. 114 (2009) 467-474.

[15] J.J Santana Rodríguez, F.J. Santana Hernández, J.E. González González, XRD and SEM studies of the layer of corrosion products for carbon steel in various different environments in the province of Las Palmas (The Canary Islands, Spain), Corros Sci. 44 (2002) 2425-2438.

[16] D.A. Koleva, K. van Breugel, J.H.W. de Wit, E. van Westing, O. Copuroglu, L. Veleva, A.L.A. Fraaij, Correlation of microstructure, electrical properties and electrochemical phenomena in reinforced mortar. Breakdown to multi-phase interface structures. Part I: Microstructural observations and electrical properties, Mater. Character. 59 (2008) 290-300. 
[17] D.A. Koleva, J.H.W. de Wit, K. van Breugel, L.P. Veleva, E. van Westing, O. Copuroglu, A.L.A. Fraaij, Correlation of microstructure, electrical properties and electrochemical phenomena in reinforced mortar. Breakdown to multi-phase interface structures. Part II: Pore network, electrical properties and electrochemical response, Mater. Character. 59 (2008) 801-815.

[18] D.C. Cook, S.J. Oh, R. Balasubramanian, M. Yamashita, The role of goethite in the formation of the protective corrosion layer on steels, Hyperfine Interact. 122 (1999) 59-70.

[19] F.R. Pérez, C.A. Barrero, O. Arnache, L.C. Sánchez, K.E. García, A.R. Hight Walker, Structural properties of iron phases formed on low alloy steels immersed in sodium chloriderich solutions, Physica B. 404 (2009) 1347-1353.

[20] R.D. Moser, P.M. Singh, L.F. Kahn, K.E. Kurtis, Chloride-induced corrosion resistance of high-strength stainless steels in simulated alkaline and carbonated concrete pore solutions, Corros Sci. 57 (2012) 241-253.

[21] A. Bautista, G. Blanco, F. Velasco, A. Gutiérrez, L. Soriano, F.J. Palomares, H. Takenouti Changes in the passive layer of corrugated austenitic stainless steel of low nickel content due to exposure to simulated pore solutions, Corros Sci. 51 (2009) 785-792.

[22] H. Luo, C.F. Dong, X.G. Li, K. Xiao, The electrochemical behaviour of 2205 duplex stainless steel in alkaline solutions with different $\mathrm{pH}$ in the presence of chloride, Electrochim Acta. 64 (2012) 211-220.

[23] A. Bautista, A. González-Centeno, G. Blanco, S. Guzmán, Application of EIS to the study of corrosion behaviour of sintered ferritic stainless steels before and after hightemperature exposure, Mater Charact. 59 (2008) 32-39. 
[24] G. Blanco, A. Bautista, H. Takenouti, EIS study of passivation of austenitic and duplex stainless steels reinforcements in simulated pore solutions, Cem Concr Comp. 28 (2006) 212-219.

[25] M. Serdar, D. Bjegović, I. Stipanović Oslaković, Corrosion resistant steel reinforcement - laboratory and field testing, Proceeding of Concrete under Severe Conditions Environment and Loading, Taylor \& Francis Group, London, 2010.

[26] M.F. Hurley, J.R. Scully, Lateral and radial corrosion propagation behavior of 9-21\% $\mathrm{Cr}$ and $18 \% \mathrm{Cr}+2.8 \%$ Mo stainless steel reinforcing materials in simulated concrete environments, Mater Corros. 64 (2013), 752-763

[27] C. Rémazeilles, $\mathrm{Ph}$. Refait, On the formation of $\beta$-FeOOH (akaganéite) in chloridecontaining environments, Corros Sci. 49 (2007) 844-857.

[28] A.L. Morales, C.A. Barrero, F. Jaramillo, C. Arroyave and J.-M. Greneche, Properties of goethite grown under the presence of $\mathrm{Cr}^{3+}, \mathrm{Cu}^{2}+$ and $\mathrm{Mn}^{2+}$ Ions, Hyperfine Interact. (2003) $148-149$

[29] T. Ishikawa, R. Katoh, A. Yasukawa, K. Kandori, T. Nakayama, F. Yuse, Influences of metal ions on the formation of $\beta$-FeOOH particles, Corros Sci. 43 (2001) 1727-1738.

[30] S. Krehula, S. Musić, The influence of a Cr-dopant on the properties of $\alpha-\mathrm{FeOOH}$ particles precipitated in highly alkaline media, J. Alloy Compd. 469 (2009) 336-342.

[31] K.E. García, C.A. Barrero, A.L. Morales, J.M. Greneche, Characterization of akaganeite synthesized in presence of $\mathrm{Al}^{3+}, \mathrm{Cr}^{3+}$, and $\mathrm{Cu}^{2+}$ ions and urea, Mater Chem Phys. $112(2008)$ 120-126. 
[32] N. Tamura, M. Kunz, K. Chen, R.S. Celestre, A.A. MacDowell, T. Warwick, A superbend X-ray microdiffraction beamline at the advanced light source, Mater Sci Eng.: A. 524 (2009) 28-32.

[33] M. Kunz, N. Tamura, K. Chen, A.A. MacDowell, R.S. Celestre, M.M. Church, S. Fakra, E.E. Domning, J.M. Glossinger, J.L. Kirschman, G.Y. Morrison, D.W. Plate, B.V. Smith, T. Warwick, V.V. Yashchuk, H.A. Padmore, E. Ustundag, A dedicated superbend xray microdiffraction beamline for materials, geo-, and environmental sciences at the advanced light source, Rev. Sci Instrum. (2009) 80.

[34] N. Tamura, A.A. MacDowell, R. Spolenak, B.C. Valek, J.C. Bravman, W.L. Brown, R.S. Celestre, H.A. Padmore, B.W. Batterman, J.R. Patel, Scanning X-ray microdiffraction with submicrometer white beam for strain/stress and orientation mapping in thin films, $J$. Synchrotron Radiat. 10 (2003) 137-143.

[35] A. Talekar, D. Chandra, R. Chellappa, J. Daemen, N. Tamura, M. Kunz, Oxidation kinetics of high strength low alloy steels at elevated temperatures, Corros Sci. 50 (2008) $2804-2815$.

[36] S. Omanovic, S.G. Roscoe, Interfacial behavior of $\beta$-Lactoglobulin at a stainless steel surface: An electrochemical impedance spectroscopy study, J. Colloid Interf Sci. 227 (2000) $452-460$.

[37] M. Farcas, N.P. Cosman, D.K. Ting, S.G. Roscoe, S. Omanovic A comparative study of electrochemical techniques in investigating the adsorption behaviour of fibrinogen on platinum, J. Electroanal. Chem. 649 (2010) 206-218. 
[38] L. Valek, S. Martinez, D. Mikulic, I. Brnardic, The inhibition activity of ascorbic acid towards corrosion of steel in alkaline media containing chloride ions, Corros Sci. 50 (2008) $2705-2709$.

[39] C. Andrade, M. Keddam, X.R. Nóvoa, M.C. Pérez, C.M. Rangel, H. Takenoutti, Electrochemical behaviour of steel rebars in concrete: influence of environmental factors and cement chemistry, Electrochim Acta. 46 (2001) 3905-3912.

[40] H. Yang, R. Lu, R.T. Downs, G. Costin, Goethite, $\alpha-\mathrm{FeO}(\mathrm{OH})$, from single-crystal data, Acta Crystallogr, E. 62 (2006) 250-252.

[41] J.E. Post, V.F. Buchwald, Crystal structure refinement of akaganeite, Am Mineral. 76 (1991) 272-277.

[42] J.K. Kim, Y.H. Kim, J.S. Lee, K.Y. Kim, Effect of chromium content on intergranular corrosion and precipitation of Ti-stabilized ferritic stainless steels, Corros Sci. 52 (2010) $1847-1852$.

[43] J. Cai, J. Liu, Z. Gao, A. Navrotsky, S.L. Suib, Synthesis and anion exchange of tunnel structure akaganeite, C-hem Mater. 13 (2001) 4595-4602. 


\section{Figure Captions}

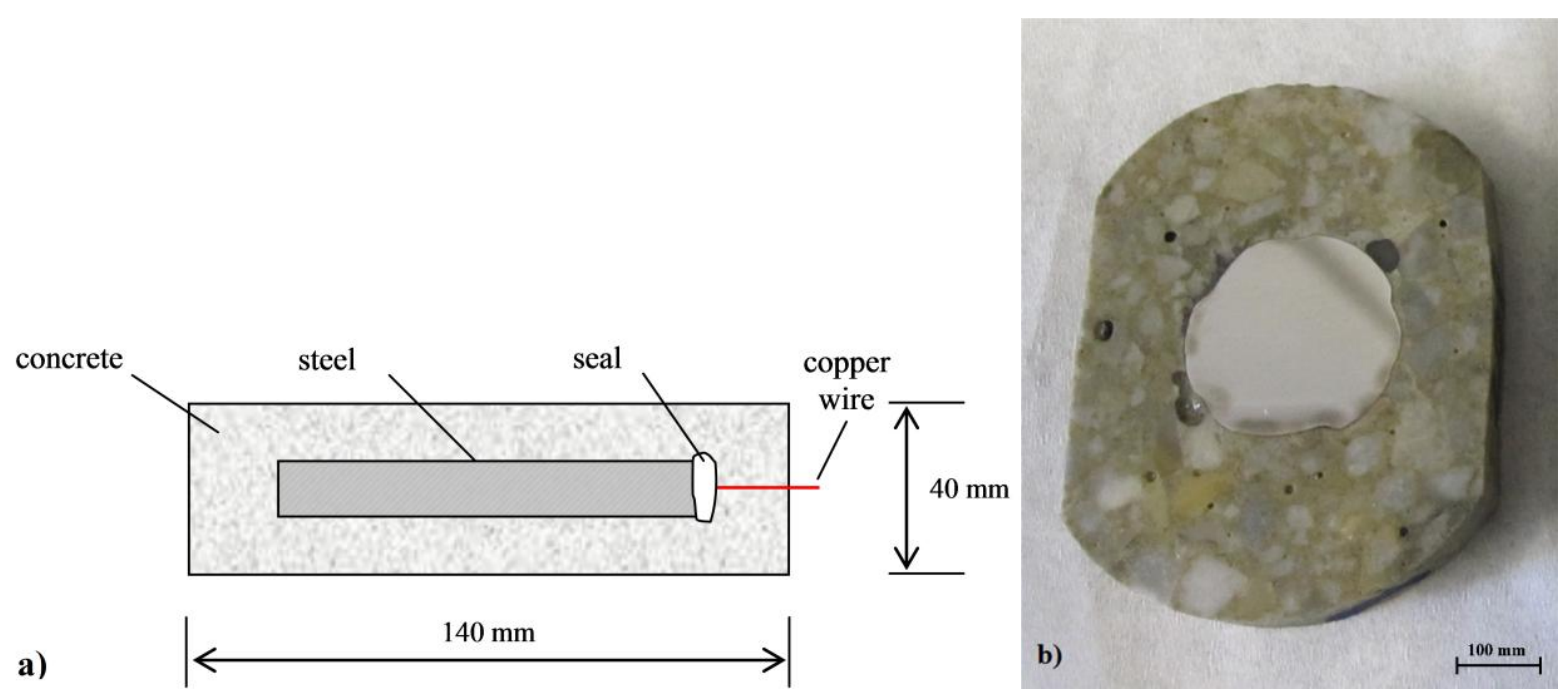

Figure 1. (a) Schematic of the cast samples; (b) Sample after sawing, grinding and polishing.

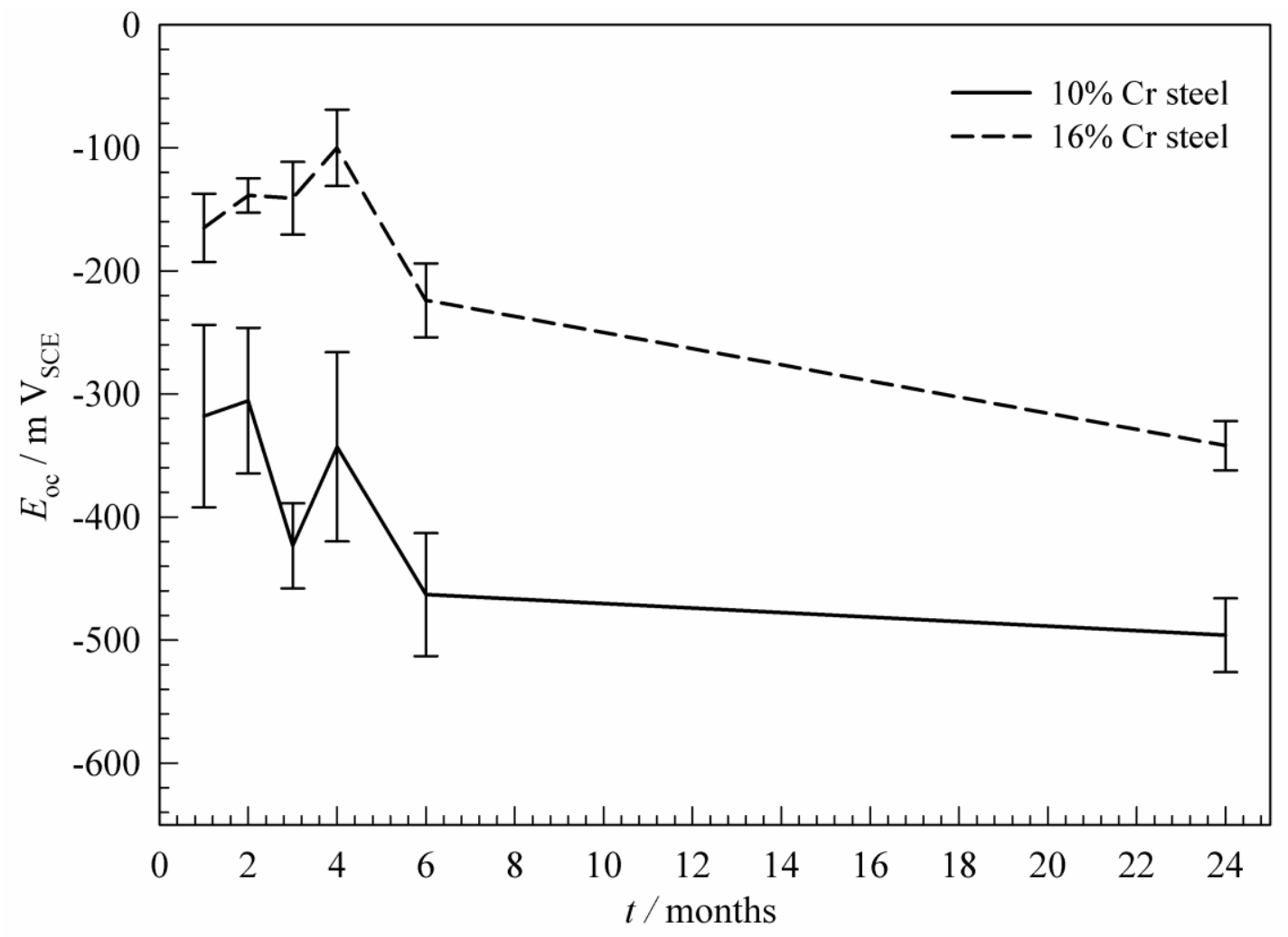

Figure 2 Open circuit potential $\left(E_{\mathrm{OC}}\right)$ of tested steels embedded into concrete during 24 months of exposure to $3.5 \% \mathrm{NaCl}$ solution. 

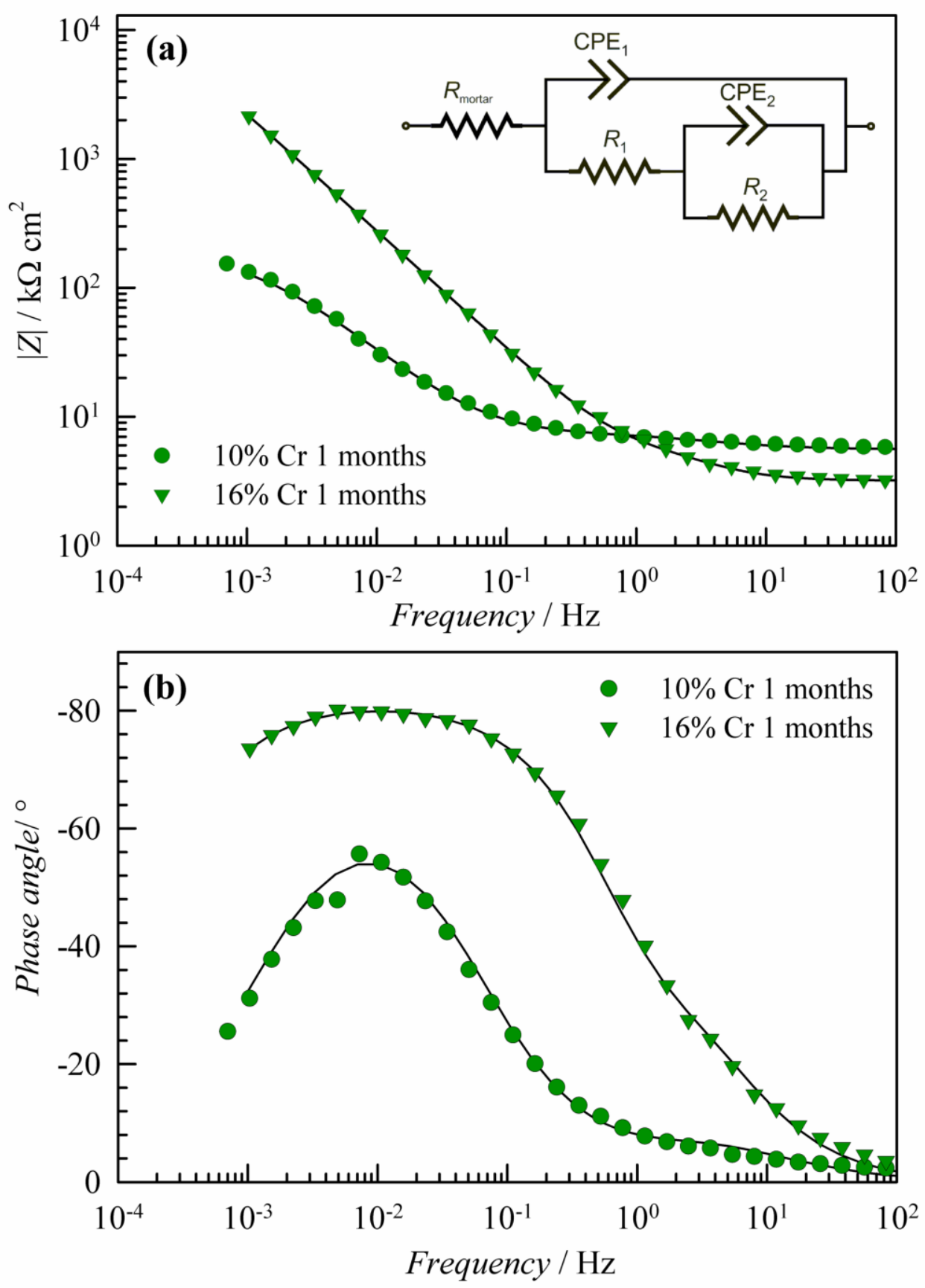

Figure 3. (a) Bode and (b) Nyquist plots of impedance spectra for concrete sample reinforced with the $10 \mathrm{wt} \% \mathrm{Cr}$ steel and the $16 \mathrm{wt} \% \mathrm{Cr}$ steel after 1 month of exposure to $3.5 \mathrm{wt} \% \mathrm{NaCl}$ solution. Proposed EC used for fitting is shown in the upper corner; experimental values given as dots, fitted values displayed as lines. 

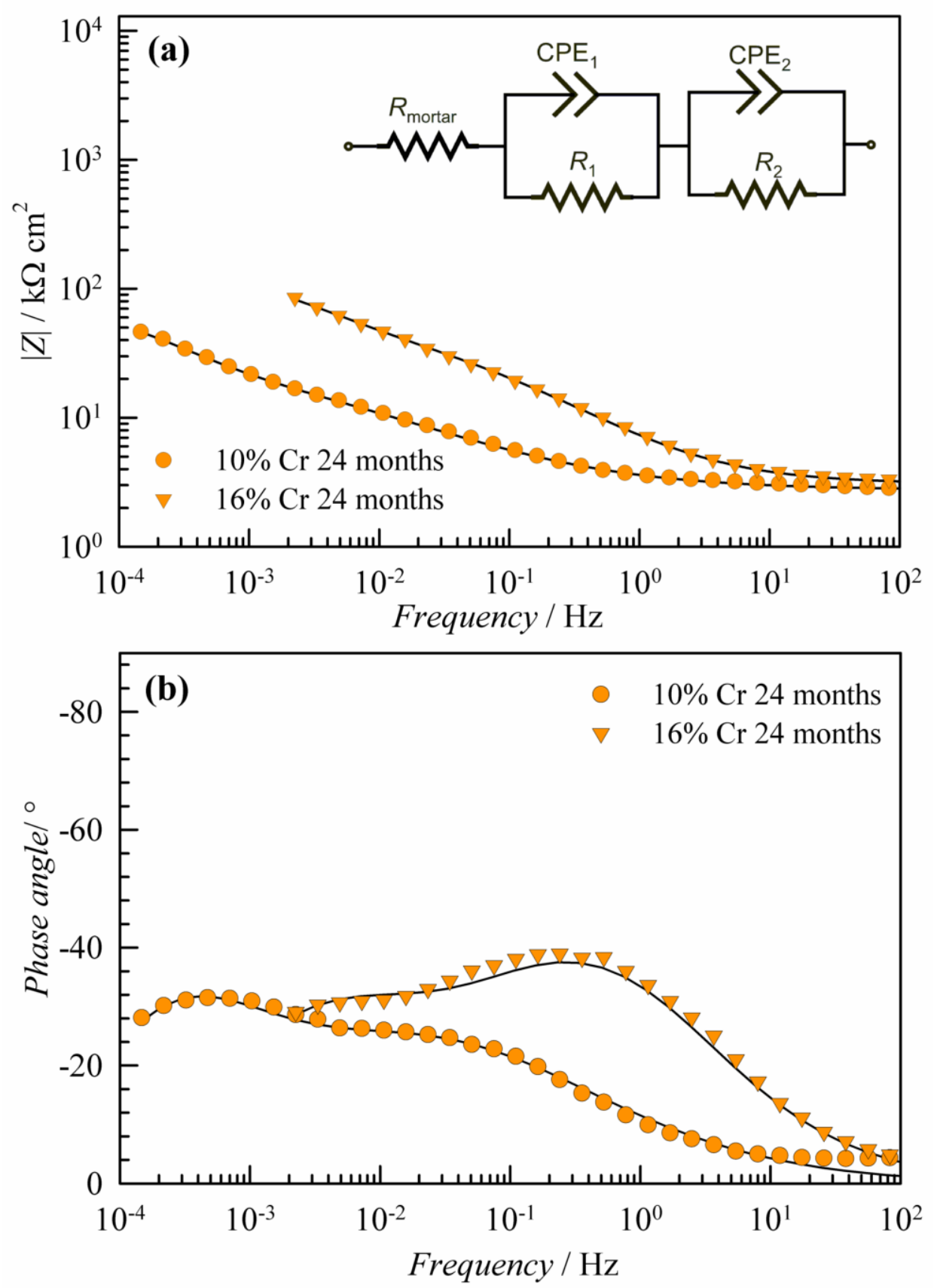

Figure 4. (a) Bode and (b) Nyquist plots of impedance spectra for concrete sample reinforced with the $10 \mathrm{wt} \% \mathrm{Cr}$ steel and the $16 \mathrm{wt} \% \mathrm{Cr}$ steel after 24 months of exposure to $3.5 \mathrm{wt} \%$ $\mathrm{NaCl}$ solution. Proposed EC used for fitting is shown in the upper corner; experimental values given as dots, fitted values displayed as lines. 


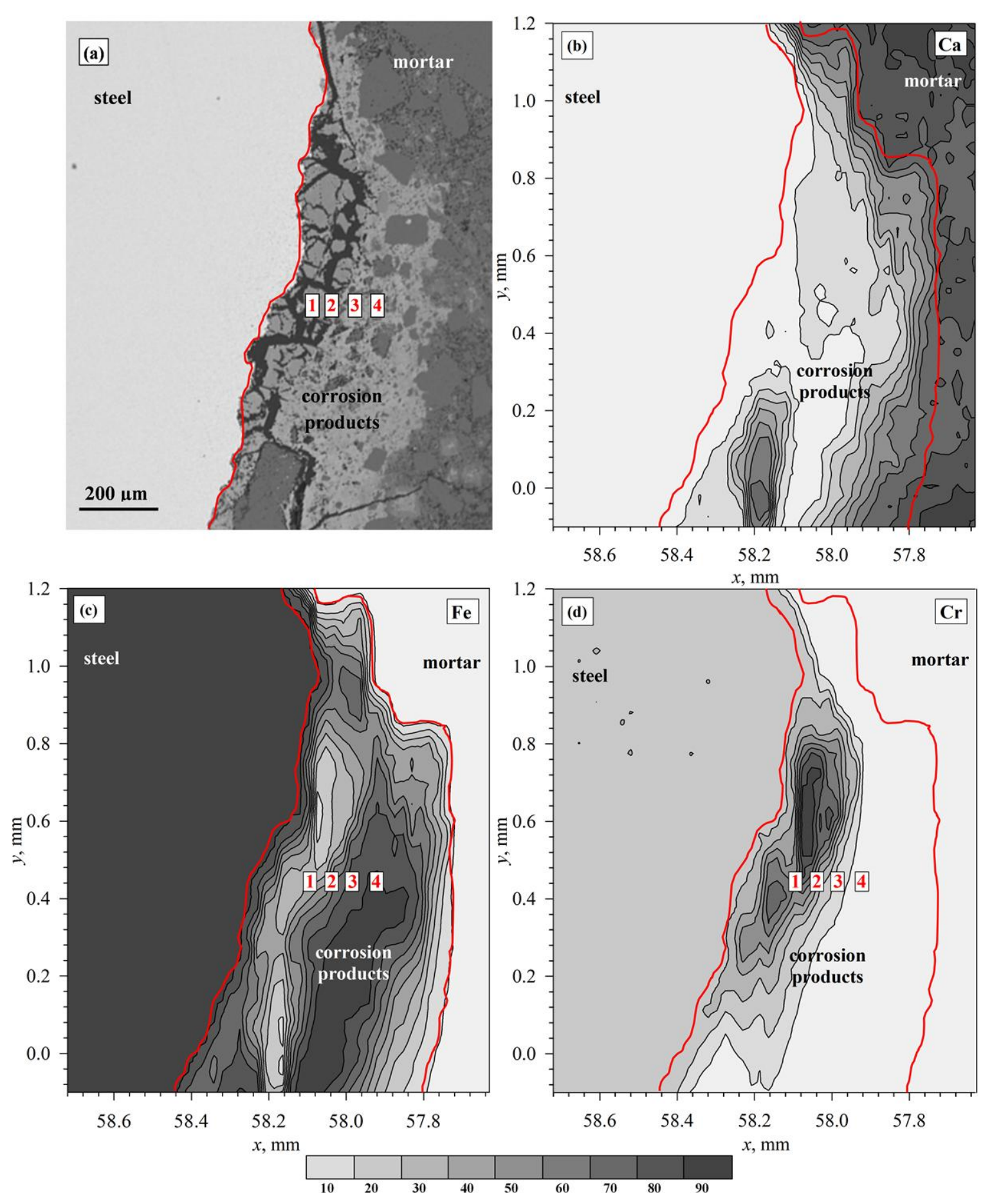

Figure 5. (a) BSE image of the $10 \mathrm{wt} \% \mathrm{Cr}$ steel and mortar interface; and $\mu$-XRF maps of the same area showing distributions and intensities of (b) calcium, (c) iron and (d) chromium. Numbers marked on the images represent the positions at which diffraction patterns presented in Figure 8 (a) were collected. 

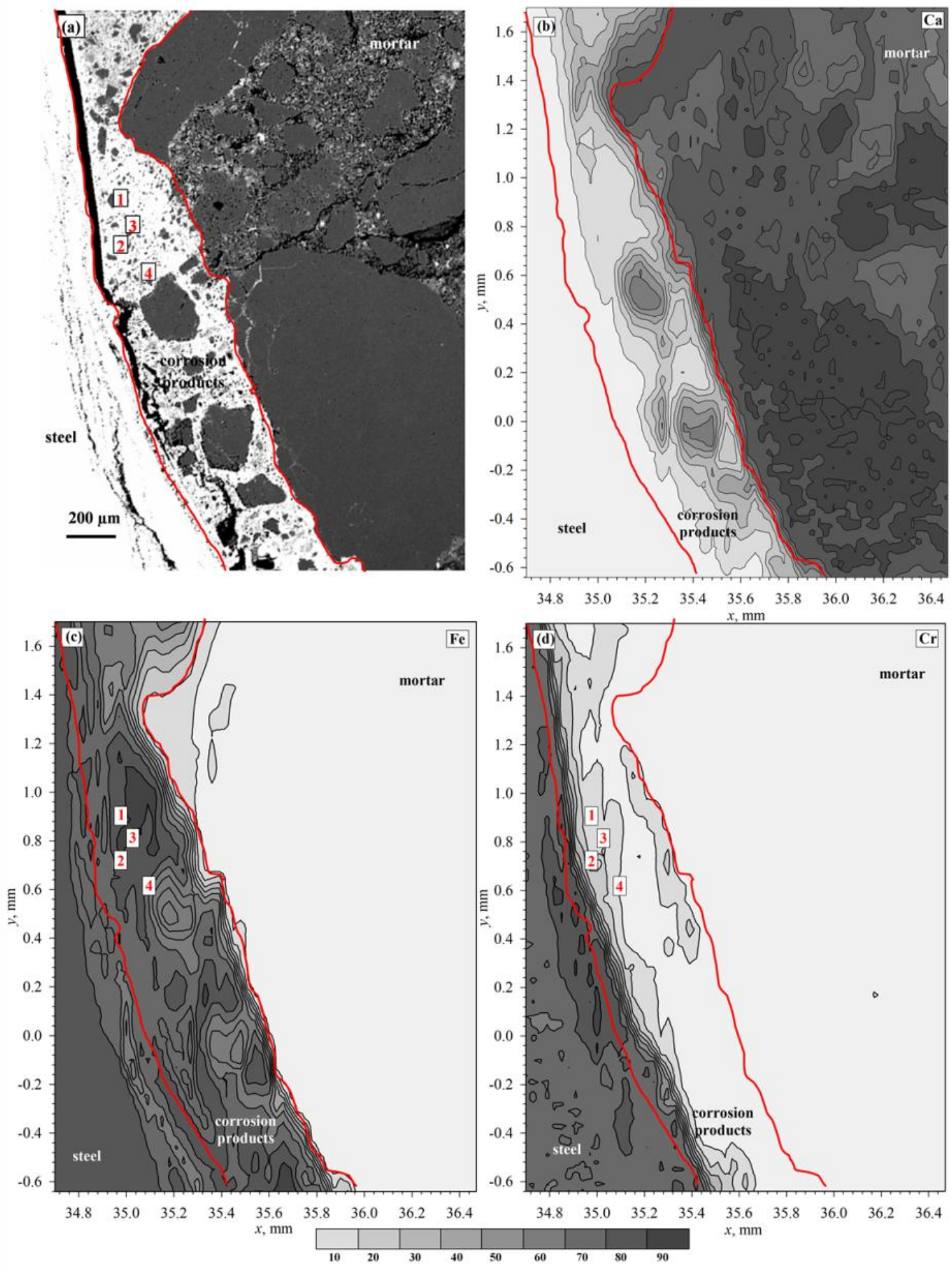

Figure 6. (a) BSE image of the $16 \mathrm{wt} \% \mathrm{Cr}$ steel and mortar interface; and $\mu$-XRF maps of the same area showing distributions and intensities of (b) calcium, (c) iron and (d) chromium. Numbers marked on the images indicate the positions at which XRD patterns in Figure 8(b) were collected. 

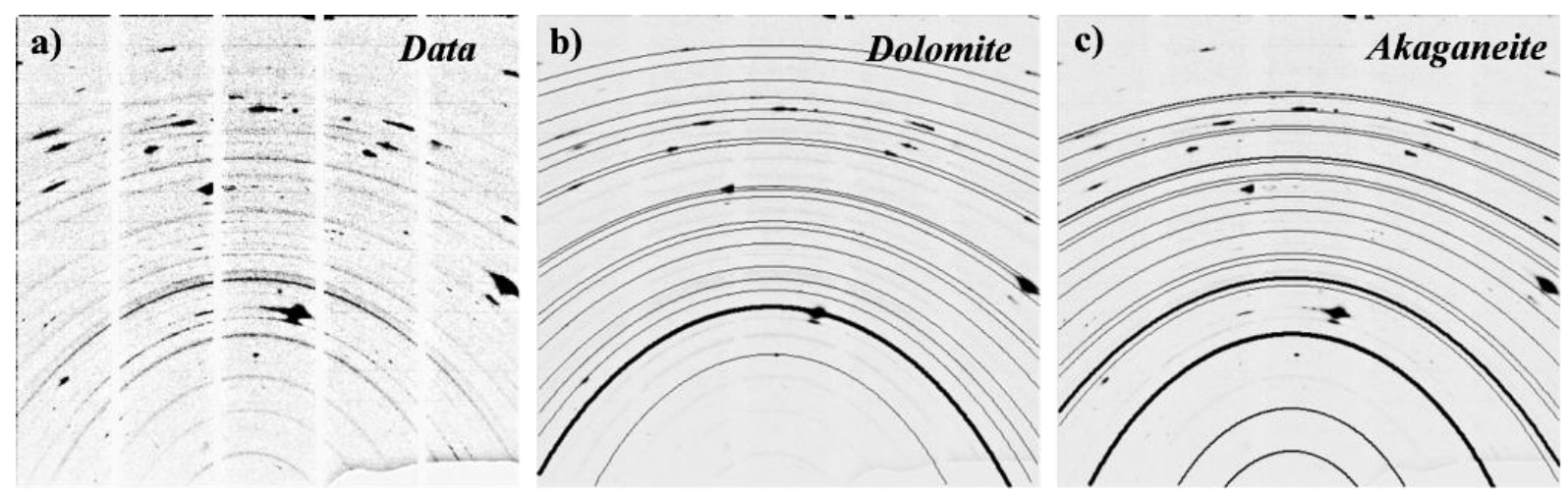

Figure 7. (a) A representative monochromatic $\mu$-XRD pattern $($ Energy $=10 \mathrm{keV})$ showing partial Debye-Scherrer rings, (b) reflections of dolomite, and (c) reflections of akaganeite.
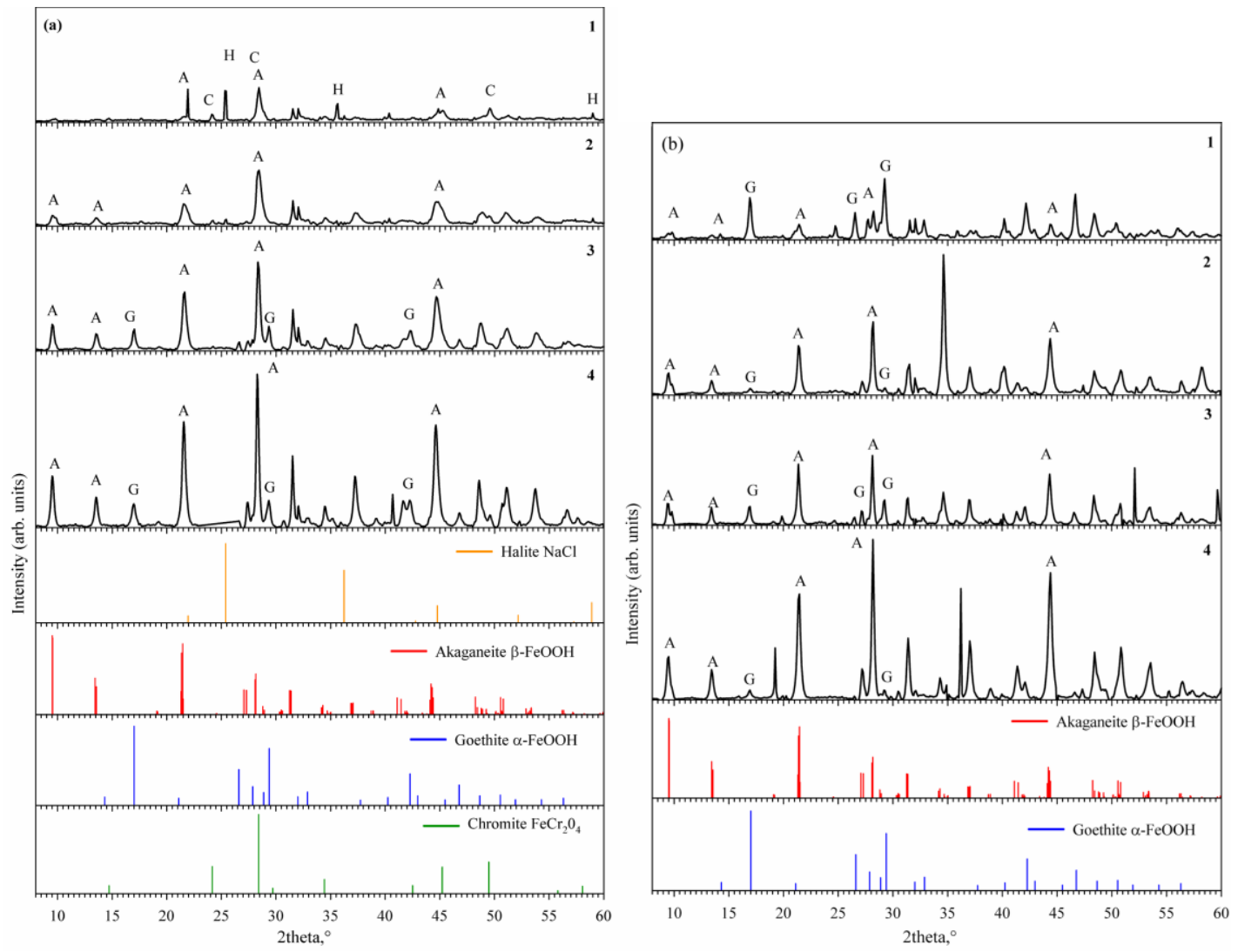

Figure 8. Radial integration of the collected $\mu$-XRD data for positions indicated on (a) Figure 4, $10 \mathrm{wt} \% \mathrm{Cr}$ steel and (b) Figure 5, $16 \mathrm{wt} \% \mathrm{Cr}$ steel. The major peaks of the identified phases are shown in the bottom of the plots where $A-$ akaganeite $(\beta-\mathrm{FeOOH}), \mathrm{G}-$ goethite $(\alpha-$ $\mathrm{FeOOH}), \mathrm{C}$ - chromite $\left(\mathrm{FeCr}_{2} \mathrm{O}_{4}\right)$, and $\mathrm{H}$ - halite $(\mathrm{NaCl})$. 

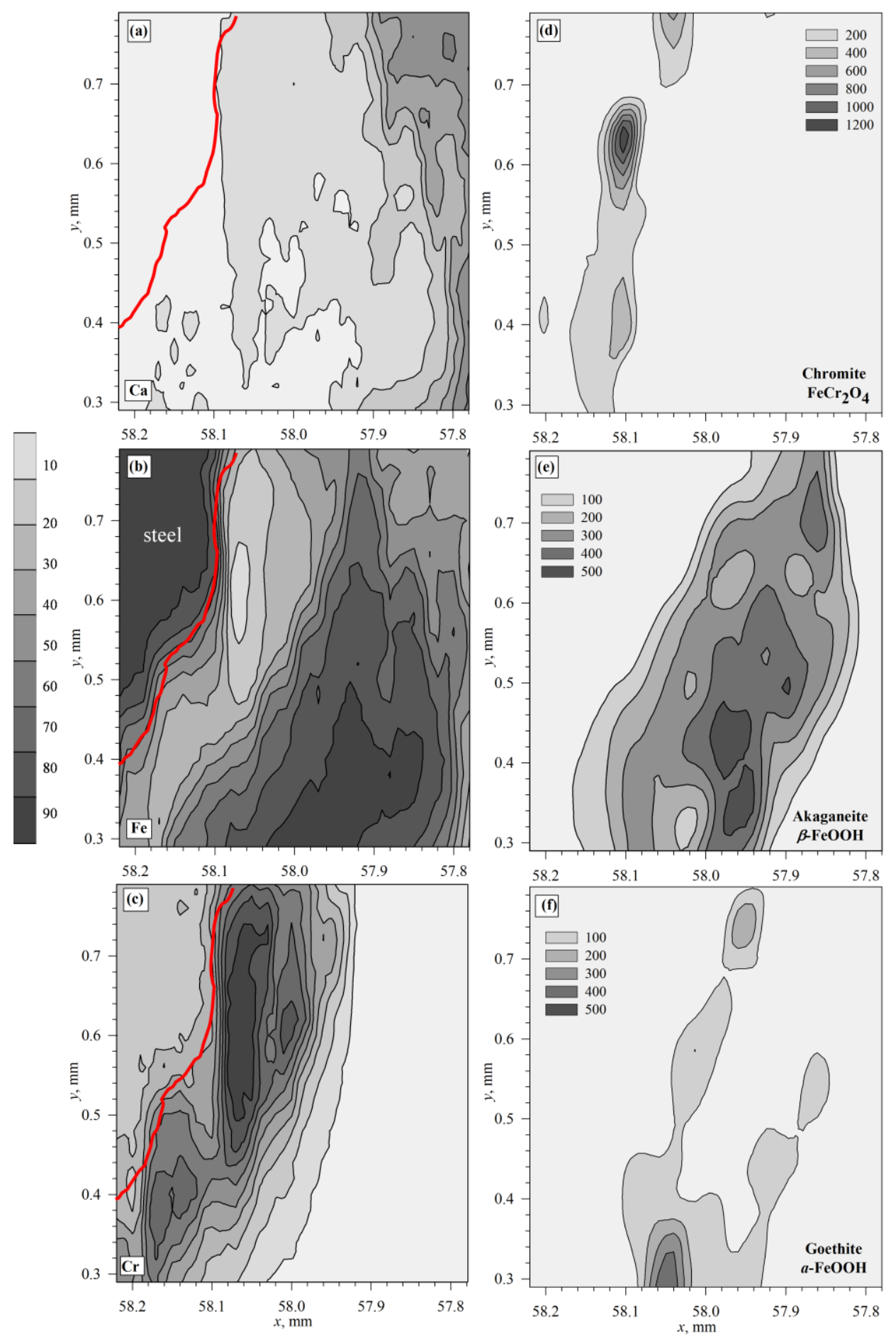

Figure 9. $10 \mathrm{wt} \% \mathrm{Cr}$ steel reinforced mortar sample: $\mu$-XRF elemental maps for (a) Ca, (b) $\mathrm{Fe}$, and (c) $\mathrm{Cr}$ and corresponding intensity maps obtained through $\mu$-XRD measurement showing distribution of (d) chromite $\left(\mathrm{FeCr}_{2} \mathrm{O}_{4}\right),(\mathrm{e})$ akaganeite $(\beta$-FeOOH$)$, and (f) goethite $(\alpha-\mathrm{FeOOH})$ 


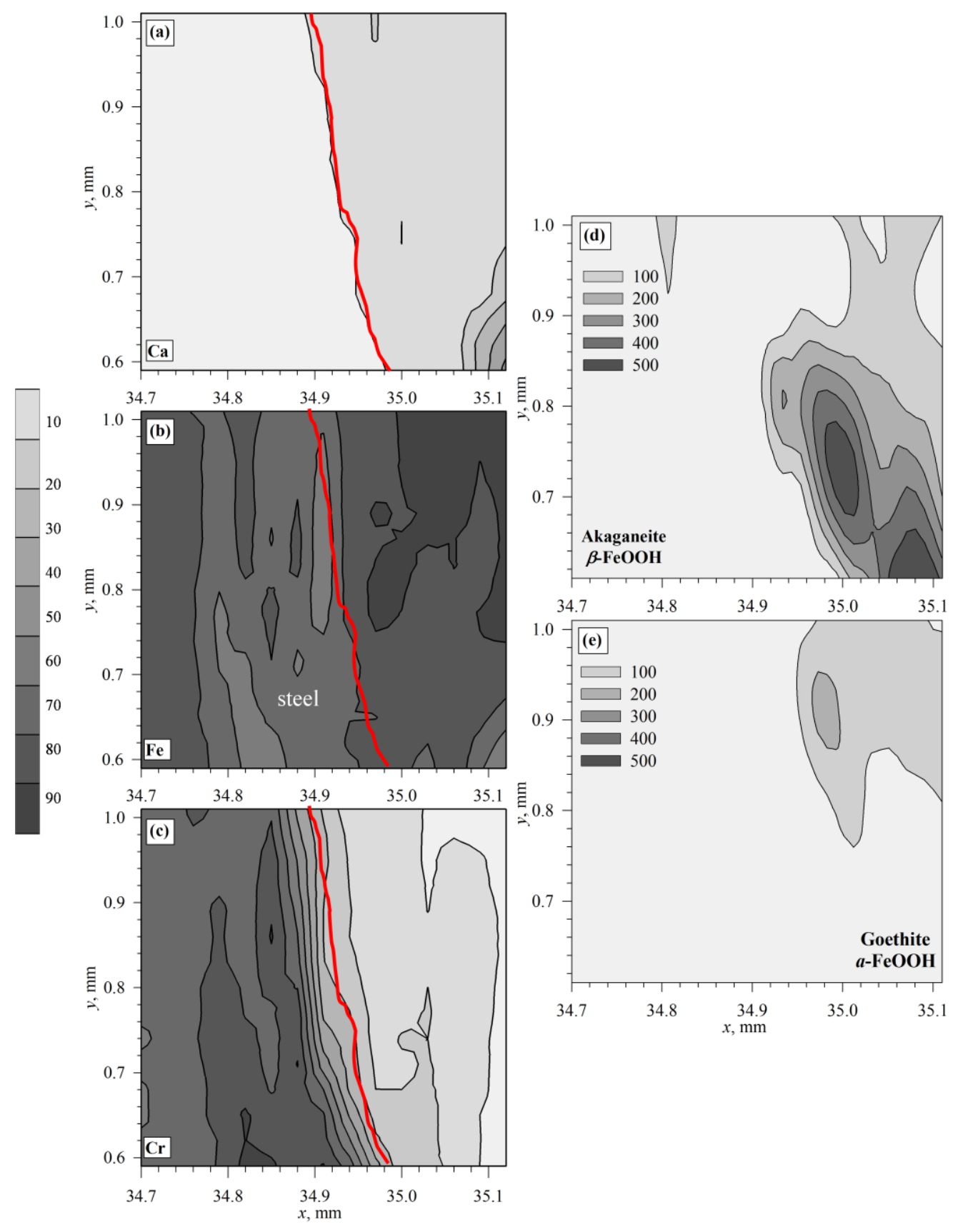

Figure 10. $16 \mathrm{wt} \% \mathrm{Cr}$ steel reinforced mortar sample: $\mu$-XRF elemental maps for (a) Ca, (b) $\mathrm{Fe}$, and (c) $\mathrm{Cr}$ and corresponding intensity maps obtained through $\mu$-XRD measurement showing distribution of (d) akaganeite $(\beta-\mathrm{FeOOH})$, and (e) goethite $(\alpha-\mathrm{FeOOH})$. 


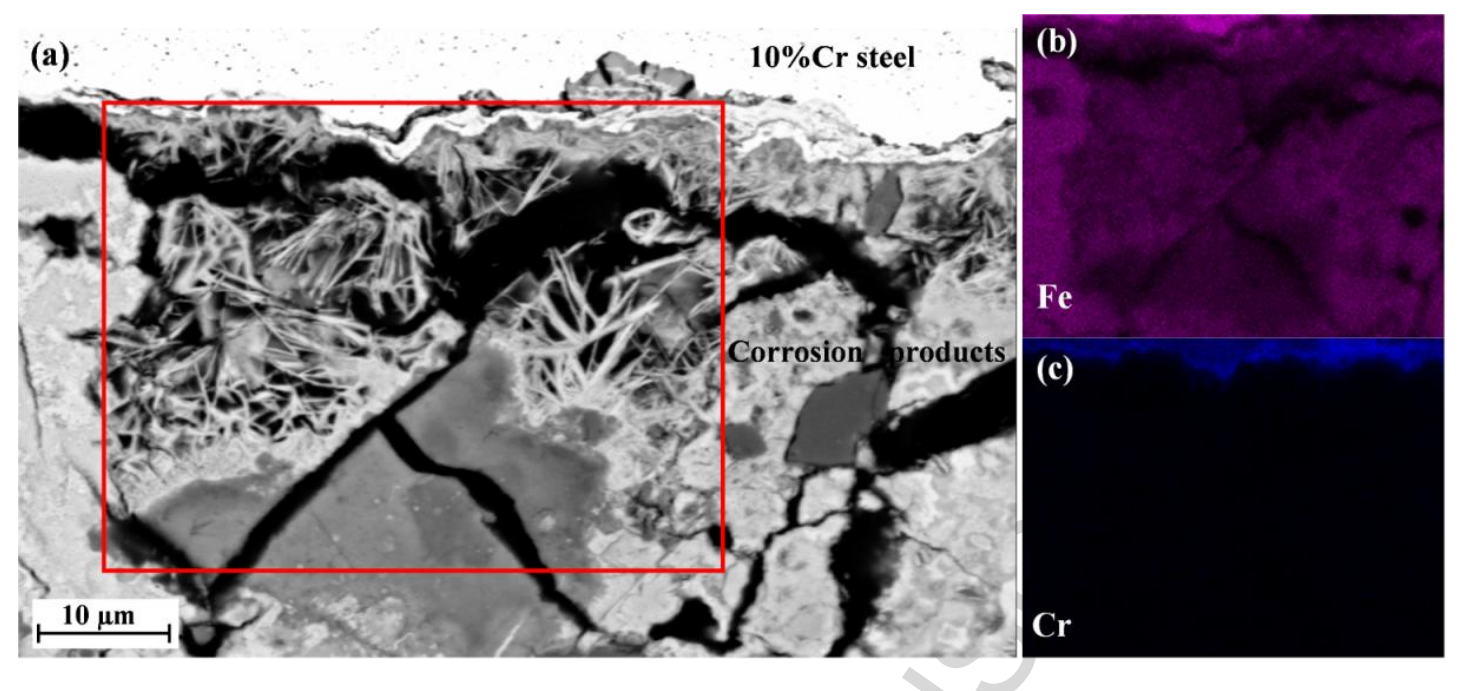

Figure 11. An example of needle-like crystals mainly formed in voids and cracks around the surface of the $10 \mathrm{wt} \% \mathrm{Cr}$ steel, BSE image (a) with $\mathrm{Fe}$ (b) and $\mathrm{Cr}$ (c) distribution maps of the area indicated in the red box on (a), obtained by EDS.

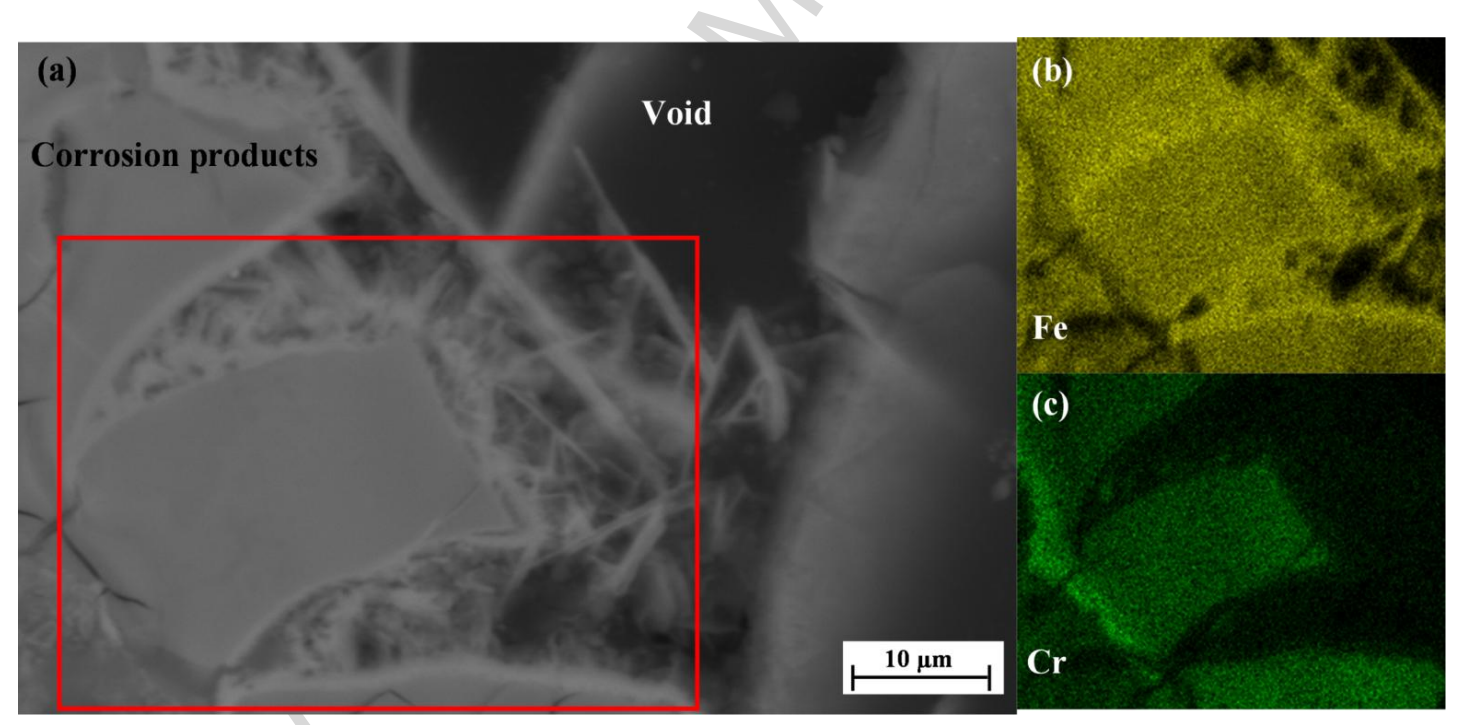

Figure 12. An example of crystals mainly formed in voids in the cement matrix around the 16 wt $\% \mathrm{Cr}$ steel, BSE image (a) with $\mathrm{Fe}(\mathrm{b})$ and $\mathrm{Cr}$ (c) distribution maps of the area indicated in the red box on (a), obtained by EDS. 
Table Captions 
Table 1. Elemental composition of the investigated steels

\section{Elemental composition, wt \%}

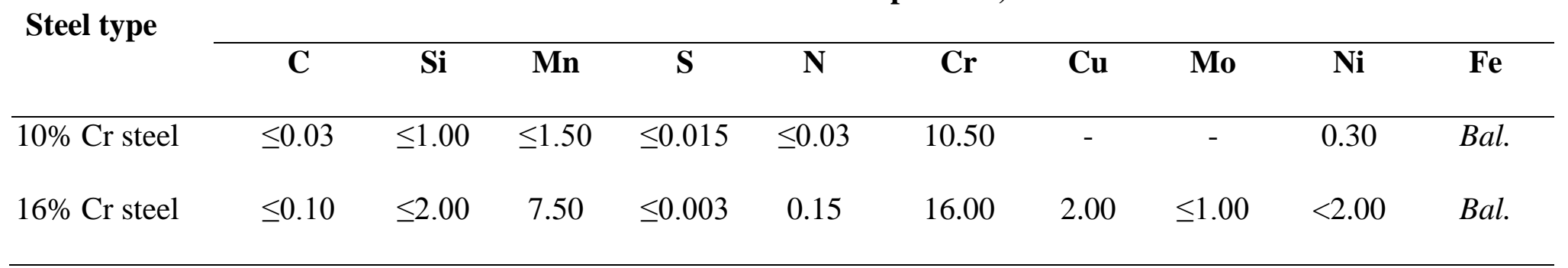

Table 2. The best-fit parameters obtained by fitting spectra for $10 \mathrm{wt} \% \mathrm{Cr}$ steel and $16 \mathrm{wt} \% \mathrm{Cr}$ steel after 1 months of exposure

\begin{tabular}{|c|c|c|c|c|c|c|c|c|}
\hline Steel type & $E_{\text {ocv }}, \mathbf{m V}_{\text {SCE }}$ & $\boldsymbol{R}_{\text {mortar }}, \mathrm{k} \boldsymbol{\Omega} \mathrm{cm}^{2}$ & $R_{1}, \mathrm{k} \Omega \mathrm{cm}^{2}$ & $C_{1}, \mu \mathrm{F} \mathrm{cm}{ }^{-2}$ & $n_{1}$ & $R_{2}, \mathrm{k} \Omega \mathrm{cm}^{2}$ & $C_{2}, \mu \mathrm{F} \mathrm{cm}{ }^{-2}$ & $n_{2}$ \\
\hline $10 \mathrm{wt} \% \mathrm{Cr}$ & -0.318 & 5.6 & 2.3 & 26.8 & 0.75 & 182.2 & 516.5 & 0.85 \\
\hline $16 \mathrm{wt} \% \mathrm{Cr}$ & -0.165 & 3.2 & 6.4 & 18.9 & 0.91 & $14,146.4$ & 37.9 & 0.91 \\
\hline
\end{tabular}

Table 3. The best-fit parameters obtained by fitting spectra for $10 \mathrm{wt} \% \mathrm{Cr}$ steel and $16 \mathrm{wt} \% \mathrm{Cr}$ steel after 24 months of exposure

\begin{tabular}{|c|c|c|c|c|c|c|c|c|}
\hline Steel type & $E_{\text {ocv }}, \mathbf{m V}_{\text {SCE }}$ & $R_{\text {mortar }}, \mathrm{k} \Omega \mathrm{cm}^{2}$ & $R_{1}, \mathrm{k} \Omega \mathrm{cm}^{2}$ & $C_{1}, \mu \mathrm{F} \mathrm{cm}^{-2}$ & $n_{1}$ & $R_{2}, \mathrm{k} \Omega \mathrm{cm}^{2}$ & $C_{2}, \mu \mathrm{F} \mathrm{cm}^{-2}$ & $n_{2}$ \\
\hline $10 \mathrm{wt} \% \mathrm{Cr}$ & -0.496 & 2.8 & 16.7 & $1,980.0$ & 0.51 & 55.5 & $24,683.1$ & 0.80 \\
\hline $16 \mathrm{wt} \% \mathrm{Cr}$ & -0.342 & 3.1 & 26.7 & 94.6 & 0.65 & 147.0 & $1,145.9$ & 0.70 \\
\hline
\end{tabular}


Table 4. Main phases identified, three reflections used for their identification, Miller indices of planes producing reflections and their $d$ spacing

\begin{tabular}{|c|c|c|c|c|}
\hline \multicolumn{2}{|l|}{ Type } & \multicolumn{3}{|c|}{ Relative intensities $I, h k l, d$-spacing $(\AA)$} \\
\hline Chromite & $\mathrm{Fe}_{2}\left(\mathrm{CrO}_{4}\right)_{3}$ & $100,311,2.53$ & $40,440,1.48$ & $34,220,2.96$ \\
\hline Goethite & $\alpha-\mathrm{FeOOH}$ & $100,101,4.20$ & $72,111,2.44$ & $45,301,2.69$ \\
\hline Akaganeite & $\beta-\mathrm{FeOOH}$ & $100,-101,7.48$ & $89,-103,3.33$ & $46,200,5.30$ \\
\hline Halite & $\mathrm{NaCl}$ & $100,200,2.83$ & $66,220,1.99$ & $22,311,1.63$ \\
\hline
\end{tabular}




\section{Figure caption}

Figure 1. (a) Schematic of the cast samples; (b) Sample after sawing, grinding and polishing.

Figure 2 Open circuit potential $\left(E_{\mathrm{OC}}\right)$ of tested steels embedded into concrete during 24 months of exposure to $3.5 \% \mathrm{NaCl}$ solution.

Figure 3. (a) Bode and (b) Nyquist plots of impedance spectra for concrete sample reinforced with the $10 \mathrm{wt} \% \mathrm{Cr}$ steel and the $16 \mathrm{wt} \% \mathrm{Cr}$ steel after 1 month of exposure to $3.5 \mathrm{wt} \% \mathrm{NaCl}$ solution. Proposed EC used for fitting is shown in the upper corner; experimental values given as dots, fitted values displayed as lines.

Figure 4. (a) Bode and (b) Nyquist plots of impedance spectra for concrete sample reinforced with the $10 \mathrm{wt} \% \mathrm{Cr}$ steel and the $16 \mathrm{wt} \% \mathrm{Cr}$ steel after 24 months of exposure to $3.5 \mathrm{wt} \%$ $\mathrm{NaCl}$ solution. Proposed EC used for fitting is shown in the upper corner; experimental values given as dots, fitted values displayed as lines.

Figure 5. (a) BSE image of the $10 \mathrm{wt} \% \mathrm{Cr}$ steel and mortar interface; and $\mu$-XRF maps of the same area showing distributions and intensities of (b) calcium, (c) iron and (d) chromium. Numbers marked on the images represent the positions at which diffraction patterns presented in Figure 8 (a) were collected.

Figure 6. (a) BSE image of the $16 \mathrm{wt} \% \mathrm{Cr}$ steel and mortar interface; and $\mu$-XRF maps of the same area showing distributions and intensities of (b) calcium, (c) iron and (d) chromium. Numbers marked on the images indicate the positions at which XRD patterns in Figure 8(b) were collected.

Figure 7. (a) A representative monochromatic $\mu$-XRD pattern (Energy $=10 \mathrm{keV}$ ) showing partial Debye-Scherrer rings, (b) reflections of dolomite, and (c) reflections of akaganeite.

Figure 8. Radial integration of the collected $\mu$-XRD data for positions indicated on (a) Figure 4, $10 \mathrm{wt} \% \mathrm{Cr}$ steel and (b) Figure 5, $16 \mathrm{wt} \% \mathrm{Cr}$ steel. The major peaks of the identified phases 
are shown in the bottom of the plots where $\mathrm{A}$ - akaganeite $(\beta-\mathrm{FeOOH}), \mathrm{G}-$ goethite $(\alpha-$ $\mathrm{FeOOH}), \mathrm{C}$ - chromite $\left(\mathrm{FeCr}_{2} \mathrm{O}_{4}\right)$, and $\mathrm{H}$ - halite $(\mathrm{NaCl})$.

Figure 9. $10 \mathrm{wt} \% \mathrm{Cr}$ steel reinforced mortar sample: $\mu$-XRF elemental maps for (a) Ca, (b) $\mathrm{Fe}$, and (c) $\mathrm{Cr}$ and corresponding intensity maps obtained through $\mu$-XRD measurement showing distribution of (d) chromite $\left(\mathrm{FeCr}_{2} \mathrm{O}_{4}\right)$, (e) akaganeite $(\beta$-FeOOH), and (f) goethite $(\alpha-\mathrm{FeOOH})$

Figure 10. $16 \mathrm{wt} \% \mathrm{Cr}$ steel reinforced mortar sample: $\mu$-XRF elemental maps for (a) Ca, (b) $\mathrm{Fe}$, and (c) $\mathrm{Cr}$ and corresponding intensity maps obtained through $\mu$-XRD measurement showing distribution of (d) akaganeite $(\beta-\mathrm{FeOOH})$, and (e) goethite $(\alpha-\mathrm{FeOOH})$.

Figure 11. An example of needle-like crystals mainly formed in voids and cracks around the surface of the $10 \mathrm{wt} \% \mathrm{Cr}$ steel, BSE image (a) with $\mathrm{Fe}(\mathrm{b})$ and $\mathrm{Cr}$ (c) distribution maps of the area indicated in the red box on (a), obtained by EDS.

Figure 12. An example of crystals mainly formed in voids in the cement matrix around the 16 wt\% Cr steel, BSE image (a) with $\mathrm{Fe}(\mathrm{b})$ and $\mathrm{Cr}$ (c) distribution maps of the area indicated in the red box on (a), obtained by EDS. 